\title{
Remote sensing and geologic studies of the Schiller-Schickard region of the Moon
}

\author{
David T. Blewett, B. Ray Hawke, Paul G. Lucey, and G. Jeffrey Taylor \\ Planetary Geosciences, Hawaii Institute of Geophysics and Planetology, and Department of Geology and Geophysics, \\ School of Ocean and Earth Science and Technology, University of Hawaii, Honolulu
}

\author{
Ralf Jaumann \\ German Aerospace Research Establishment, Institute for Planetary Exploration, Berlin, Germany
}

\author{
Paul D. Spudis \\ Lunar and Planetary Institute, Houston, Texas
}

\begin{abstract}
Near-infrared reflectance spectra, multispectral images, and photogeologic data for the Schiller-Schickard (SS) region were obtained and analyzed in order to determine the composition and origin of a variety of geologic units. These include light plains deposits, Orientale-related deposits, mare units, and dark-haloed impact craters (DHCs). Spectral data indicate that the preOrientale highland surface was dominated by noritic anorthosite. Near-IR spectra show that DHCs in the region have excavated ancient $(>3.8 \mathrm{Ga}$ ) mare basalts from beneath highland-bearing material emplaced by the Orientale impact. Ancient mare basalts were widespread in the SS region prior to the Orientale event, and their distribution appears to have been controlled by the presence of several old impact basins, including the Schiller-Zucchius basin and a basin previously unrecognized. Both near-IR spectra and multispectral images indicate that light plains and other Orientale-related units in the SS region contain major amounts of local, pre-Orientale mare basalt. The amounts of local material in these deposits approach, but seldom exceed, the maximum values predicted by the local mixing hypothesis of Oberbeck and co-workers.
\end{abstract}

\section{Introduction}

The area around the craters Schiller and Schickard, near the extreme southwestern limb of the Moon's Earth-facing hemisphere (Figure 1), contains numerous unusual features which have provoked controversy since the early days of lunar study. These include the crater Wargentin, whose floor is topographically higher than the surrounding terrain; the SchillerZucchius impact basin [Hartmann and Wood, 1971]; the large crater Schickard (diameter $227 \mathrm{~km}$ ), whose floor contains distinct mare deposits as well as a light plains unit; the elongated crater Schiller; a high density of dark-haloed impact craters [Schultz and Spudis, 1979]; and Orientale secondary craters (Figure 2). We chose to study several of these features in detail because of their possible significance in understanding the complex geologic history of the region.

A number of light plains deposits are found in the SchillerSchickard region. The nature and origin of light plains have been a long-standing problem in lunar geology. This flat, smooth landform, which covers some $4-7 \%$ of the nearside [Oberbeck et al., 1974], often appears to have ponded in depressions and is characterized by crater densities and albedos intermediate between those of the highlands and the maria. Prior to the Apollo 16 mission in 1972, light plains were interpreted by some geologic mappers to be of volcanic origin, perhaps ash sheets or

Copyright 1995 by the American Geophysical Union.

Paper number 95JE01409.

0148-0227/95/95JE-01409\$05.00 low-viscosity silicic lavas [e.g., Hackman, 1966; Milton and Hodges, 1972; Wilhelms, 1976]. Apollo 16 sampled the Cayley Formation, an archetypal light plains unit, and discovered nonvolcanic breccias, forcing a reinterpretation of the origin of light plains units [e.g., Eggleton and Schaber, 1972; Wilhelms, 1976, 1987].

Currently, several origins for light plains are recognized [Blewett et al., 1993; Head et al., 1993b]. These include possible true volcanic light plains (the Apennine Bench formation [Hawke and Head, 1978; Spudis, 1978; Spudis et al., 1988]); and plains containing much impact melt (Orientale interior [Head, 1974]). A third type of light plains is thought to be related to the emplacement of ejecta from basin-forming impacts [Eggleton and Schaber, 1972]. Since Apollo, the important role of ballistic erosion and sedimentation in lunar stratigraphy has been emphasized [Oberbeck, 1975]. A key question concerning the ballistic erosion model of basin ejecta emplacement is the role of "local mixing" in the formation of the distal basin deposits. Local mixing refers to the disruption of the preimpact surface by secondary craters and the incorporation of this local material with primary ejecta in the resulting deposit.

The light plains in the Schiller-Schickard (SS) region represent an important subtype of the basin ejecta-related light plains, involving the burial of mare basalts. Remote sensing studies by Hawke and Bell [1981] and Bell and Hawke [1984] have confirmed the hypothesis of Schultz and Spudis [1979] that the dark-haloed impact craters (DHCs) in the SS region formed when ancient mare basalts were excavated from beneath a higheralbedo plains unit emplaced by the Orientale basin-forming impact. A hidden mare deposit of this kind has been referred to 


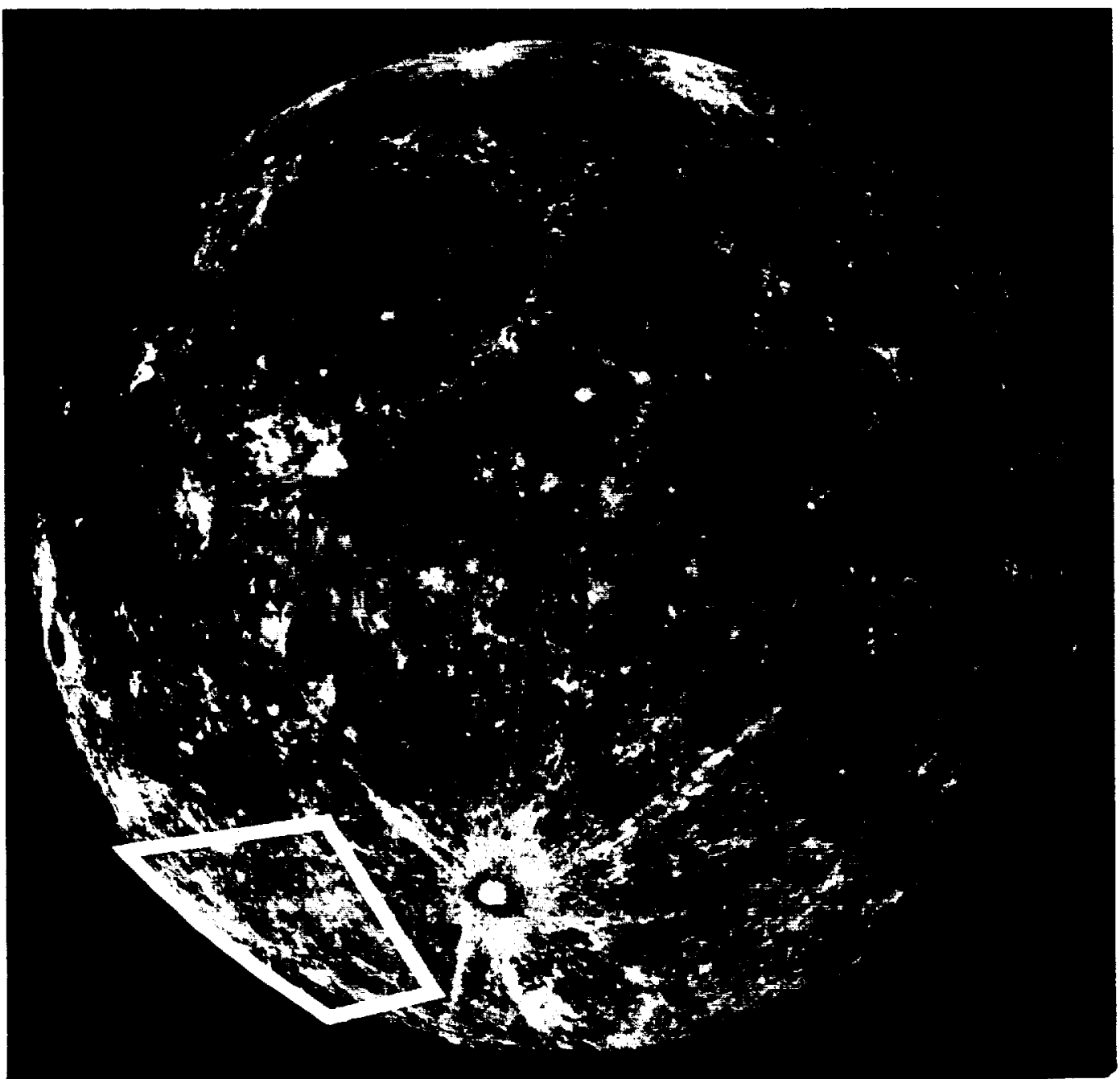

Figure 1. Full-Moon photograph showing the location of the Schiller-Schickard region. The box approximates the area shown in Figure 2.

as a "cryptomare" [Head and Wilson, 1992]. The flat expanse of the ancient mare may have provided a favorable site for deposition of light plains by the action of the debris surge initiated by Orientale secondary-forming projectiles [Bell and Hawke, 1984]. The preliminary spectral studies of Blewett et al. [1991, 1992] and observations by the Galileo spacecraft during its first Earth-Moon encounter [Belton et al., 1992; Head et al., 1993a] showed that the light plains in the floor of Schickard have a greater mafic mineral content than the surrounding highlands. This was attributed to the presence of a mare basalt component. The amount of mare basalt included in the Schickard light plains is a measure of the extent of local mixing that occurred in the area.

This paper reports on work undertaken to increase our understanding of the interesting Schiller-Schickard region. Major goals of the study include the following: (1) to determine the composition of surface units in the area, (2) to investigate the nature and origin of the Schickard cryptomare, (3) to test the local mixing hypothesis as proposed by Oberbeck and coworkers, (4) to examine the modes of emplacement of the distal deposits of lunar impact basins, (5) to develop ideas concerning the relationship between cryptomaria and old impact basins, and (6) to report a previously unrecognized multiring impact structure.

\section{Methods}

\section{Collection and Analysis of Near-IR Spectra}

The majority of the near-infrared reflectance spectra used in this study were recorded with the Planetary Geosciences InSb spectrometer mounted on the University of Hawaii $2.24-\mathrm{m}$ telescope at Mauna Kea Observatory. A small number of spectra were obtained with a $61-\mathrm{cm}$ telescope. The instrument successively measures the intensity in 120 channels between 0.6 and $2.5 \mu \mathrm{m}$ by rotating a filter with continuously variable band pass in front of the detector. Circular apertures in the telescope focal plane admit moonlight to the detector; aperture sizes of 0.7 or 2.3 arc sec were employed. The resulting spot sizes on the lunar surface were -1.5 or $\sim 4.5 \mathrm{~km}$ average diameter under optimum observing conditions. Observational and data reduction techniques were standard, and details can be found elsewhere [McCord et al., 1981].

Iron-bearing pyroxenes are responsible for absorption bands in lunar spectra near $1 \mu \mathrm{m}$. The shape and position of this band provide information on the composition of the pyroxene [Adams, 1974]. In order to extract this information, the method of Lucey et al. [1986] was employed. First, a straight line is fit to the reflectance "peaks" on either side of the $1 \mu \mathrm{m}$ band (usually near 0.7 and $1.6 \mu \mathrm{m})$. The slope of this line $(\Delta$ scaled reflectance/ $\Delta \lambda)$ 
defines a useful spectral parameter known as the continuum slope. Next, the continuum is removed by dividing the spectrum by the continuum line. The shape of the absorption band in the resulting continuum-removed spectrum is modeled by fitting it with a cubic polynomial. The equation of the polynomial in conjunction with straight lines fit to the sides of the band yields four band parameters: the band's wavelength position of reflectance minimum, depth, full width at half maximum depth, and asymmetry. The asymmetry parameter (not described in Lucey et al.'s [1986] work) is the ratio of the band's width shortward of the band minimum to the width longward of the band minimum.

Of principal interest for determining mineralogy are the position of the band minimum and its depth. Spectra for mare basalt surfaces generally have relatively deep bands with minima at $>0.95 \mu \mathrm{m}$, indicating high-Ca pyroxene. The low-Ca orthopyroxenes of highland mineral assemblages produce bands with minima shortward of $0.95 \mu \mathrm{m}$. Since highland rocks commonly have lower abundances of mafic minerals, the $1 \mu \mathrm{m}$ bands are shallower. Over 35 spectra for features in the SS region were obtained, including mature mare surfaces, mare craters, DHC interior and ejecta deposits, light plains surfaces, and a highland crater. Selected representative spectra are shown in Figures 3, 4, and 5; the locations for which the spectra were obtained are shown on Figure $2 c$. The spectra shown in Figures 3-5 have not been corrected for thermal emission, and some show the effects of incomplete removal of atmospheric water absorptions near 1.4 and $1.9 \mu \mathrm{m}$. Derived spectral parameters are listed in Table 1.
In order to gain further insight into the data set, the multivariate statistical technique of principal components analysis (PCA) was applied. A method of using PCA for spectral data was developed by Smith et al. [1985] and applied to lunar telescopic and sample spectra by Johnson et al. [1985] and Pieters et al. [1985]. More recently, Jaumann [1991] utilized PCA in a study of laboratory lunar sample spectra and their relationship to chemical composition. PCA reduces the dimensionality of the data to a small number of factors related to the causes of the variation, aiding in the selection of spectral endmembers and revealing mixing trends. To apply PCA to the SS spectra, a computer program to perform the statistical calculations described by Smith et al. [1985] was written and checked with example data sets from chapter 6 of Davis [1986]. Twenty-five of the best quality SS spectra (over Sun) were selected for inclusion in the PCA. Portions of the spectra in the vicinity of telluric water bands (near 1.4 and $1.9 \mu \mathrm{m}$ ) and longward of $2 \mu \mathrm{m}$ (thermal contamination) were not included in the analysis. The spectra thus were defined by reflectances at 69 wavelengths between 0.67 and $1.81 \mu \mathrm{m}$. A laboratory spectrum of an Apollo 16 soil sample, which represents the spectrum of the Apollo 16 standard telescopic observing site [McCord et al., 1981], was also included in the PCA. The Apollo 16 standard site is an excellent spectral match for the western limb highlands [Hawke et al., 1991]. Absolute albedo information is not preserved in the telescopic observations, so the spectra were all scaled to 1.0 at $1.02 \mu \mathrm{m}$.

The variance-covariance matrix of the spectral data matrix was calculated, and the eigenvectors and eigenvalues extracted. The

Table 1. Spectral Parameters Derived for Schiller-Schickard Spectra

\begin{tabular}{|c|c|c|c|c|c|c|}
\hline Spectrum & Spot Name & $\begin{array}{c}\text { Band Minimum, } \\
\mu \mathrm{m}\end{array}$ & $\begin{array}{l}\text { Continuum } \\
\text { Slope, } 1 / \mu \mathrm{m}\end{array}$ & Band Depth, $\%$ & $\begin{array}{c}\text { FWHM,* } \\
\mu \mathrm{m}\end{array}$ & Asymmetry \\
\hline 3 & Apollo 16 & 0.90 & 0.59 & 2.7 & 0.19 & 0.66 \\
\hline 4 & Schiller-Zucchius Plains S & 0.96 & 0.63 & 6.0 & 0.35 & 0.65 \\
\hline 5 & Schiller-Zucchius Plains N & 0.98 & 0.63 & 6.0 & 0.28 & 0.89 \\
\hline 6 & Schiller-Zucchius Plains 3 & 0.95 & 0.68 & 6.6 & 0.26 & 0.63 \\
\hline 7 & Schiller floor & 0.93 & 0.60 & 6.1 & 0.29 & 0.61 \\
\hline 8 & Noggerath F bowl 1 & 0.98 & 0.53 & 21.7 & 0.28 & 0.79 \\
\hline 9 & Noggerath F bowl 2 & 0.97 & 0.50 & 20.5 & 0.27 & 0.83 \\
\hline 10 & Noggerath F bowl 3 & 0.98 & 0.55 & 18.9 & 0.28 & 0.87 \\
\hline 12 & Noggerath F ejecta 1 & 0.98 & 0.66 & 11.2 & 0.25 & 0.93 \\
\hline 13 & Noggerath F ejecta 2 & 0.97 & 0.67 & 12.0 & 0.25 & 0.75 \\
\hline 14 & Noggerath F ejecta 3 & 0.99 & 0.65 & 8.4 & 0.22 & 1.16 \\
\hline 15 & Drebbel F ejecta 1 & 0.95 & 0.64 & 6.1 & 0.26 & 0.67 \\
\hline 16 & Drebbel F ejecta 2 & 0.98 & 0.66 & 6.8 & 0.26 & 0.93 \\
\hline 17 & Drebbel F ejecta 3 & 0.95 & 0.67 & 5.0 & 0.21 & 0.95 \\
\hline 18 & Inghirami $\mathbf{W}$ & 0.98 & 0.66 & 7.1 & 0.28 & 0.85 \\
\hline 19 & Inghirami W bowl 1 & 0.99 & 0.60 & 10.6 & 0.26 & 1.14 \\
\hline 20 & Inghirami $W$ bowl 2 & 0.95 & 0.59 & 14.1 & 0.29 & 0.72 \\
\hline 21 & Wargentin DHC & 0.99 & 0.65 & 5.2 & 0.28 & 1.53 \\
\hline 22 & Lacus Excellentiae & 0.97 & 0.64 & 7.6 & 0.29 & 0.78 \\
\hline 23 & Schickard mare N 1 & 0.97 & 0.69 & 8.6 & 0.29 & 0.72 \\
\hline 24 & Schickard mare $\mathbf{N} 2$ & 0.96 & 0.70 & 8.3 & 0.23 & 0.76 \\
\hline 25 & Schickard mare N 3 & 0.98 & 0.70 & 8.2 & 0.25 & 1.04 \\
\hline 26 & Schickard mare crater 1 & 0.96 & 0.64 & 14.8 & 0.27 & 0.83 \\
\hline 27 & Schickard mare crater 2 & 0.99 & 0.61 & 13.3 & 0.29 & 1.34 \\
\hline 28 & Schickard mare S & 1.00 & 0.69 & 8.8 & 0.29 & 0.77 \\
\hline 30 & Schickard $\times 1$ & 0.96 & 0.53 & 6.2 & 0.33 & 0.80 \\
\hline 31 & Schickard X 2 & 0.92 & 0.49 & 5.3 & 0.19 & 0.87 \\
\hline 33 & Schickard R & 0.98 & 0.67 & 9.5 & 0.28 & 0.84 \\
\hline 34 & Schickard center & 0.94 & 0.63 & 4.8 & 0.30 & 0.77 \\
\hline 35 & Schickard Light Plains 1 & 0.94 & 0.61 & 5.1 & 0.22 & 0.66 \\
\hline 36 & Schickard Light Plains 2 & 0.96 & 0.60 & 4.8 & 0.23 & 0.90 \\
\hline 37 & Schickard Light Plains crater I & 0.96 & 0.44 & 20.1 & 0.27 & 0.86 \\
\hline 38 & Schickard Light Plains crater 2 & 0.96 & 0.62 & 12.0 & 0.33 & 0.81 \\
\hline 40 & Schiller-Zucchius Plains 4 & 0.96 & 0.60 & 8.1 & 0.29 & 0.79 \\
\hline 41 & Schiller-Zucchius Plains 5 & 0.95 & 0.65 & 7.3 & 0.27 & 0.48 \\
\hline
\end{tabular}

*Band full width at half maximum. 


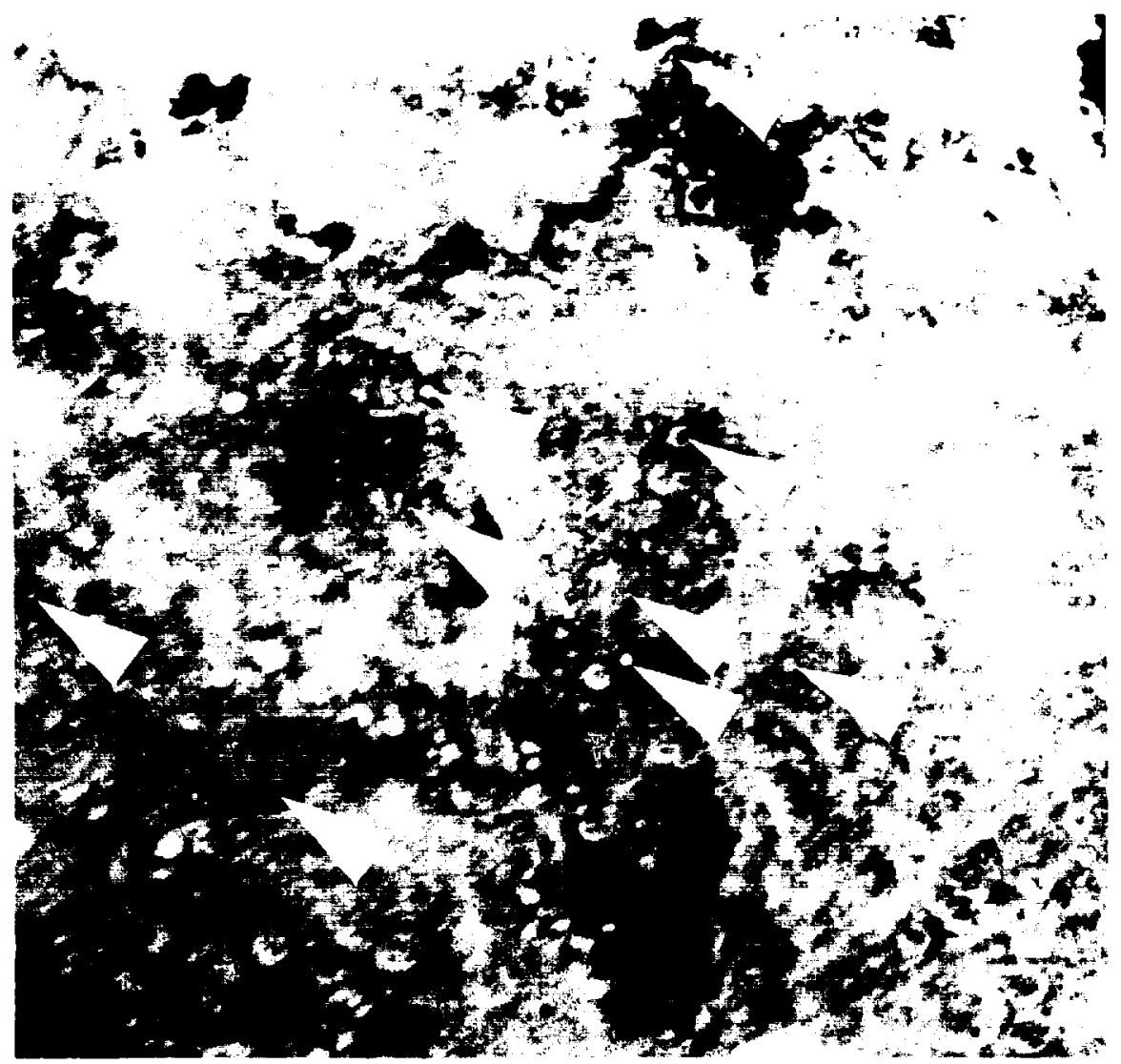

Figure 2a. Rectified Earth-based telescopic photo of the Schiller-Schickard region at high Sun angle (part of Plate 23-c of Whitaker et al. [1963]). Selected dark-haloed impact craters are indicated by the arrows. North is to the top, length of arrows $\mathbf{8 2} \mathrm{km}$. For identification of features, refer to the sketch map in Figure $\mathbf{2 c}$.

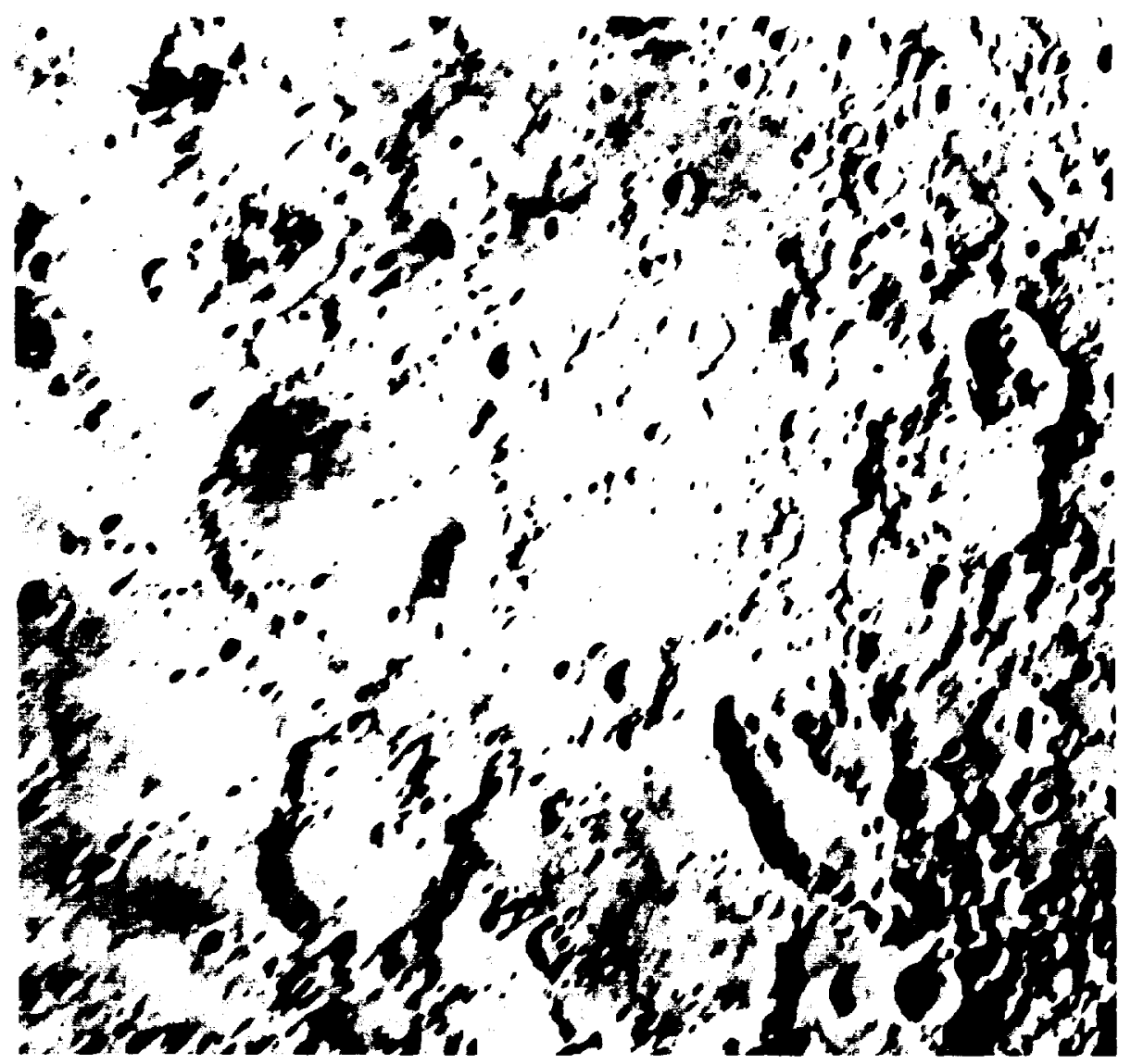

Figure 2b. Rectified Earth-based telescopic photo of the Schiller-Schickard region at low Sun angle (part of Plate 23-d of Whitaker et al. [1963]). North is to the top, scale approximately the same as Figure 2a. 


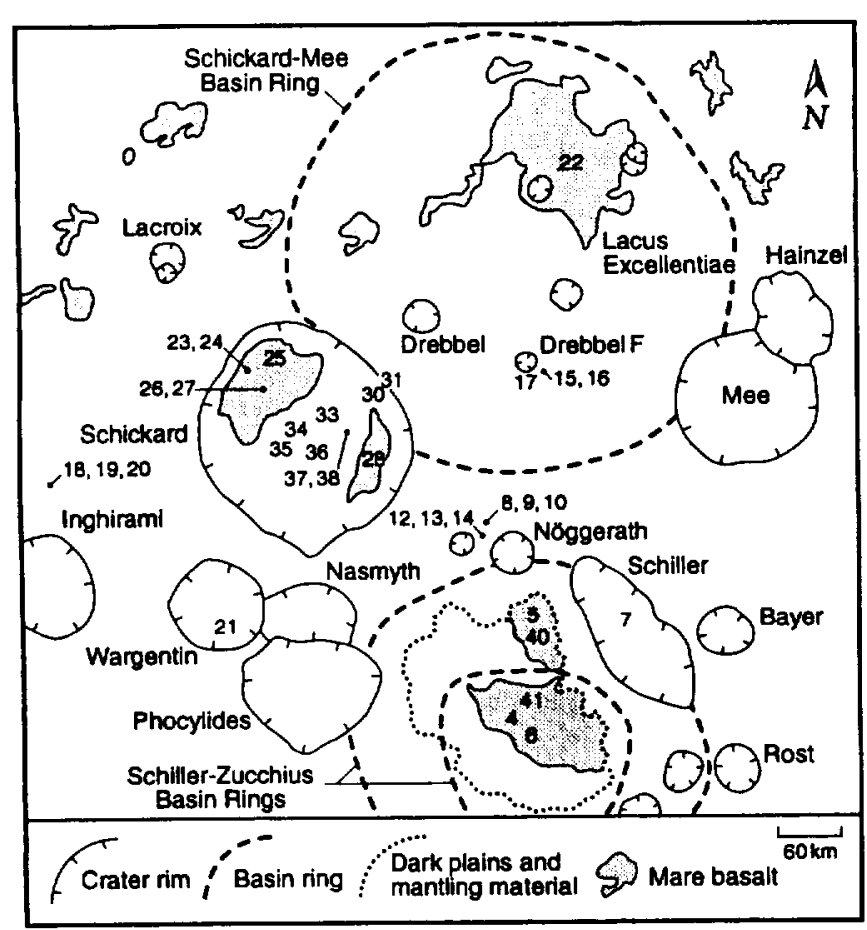

Figure 2c. Geologic sketch map of the Schiller-Schickard region. Major features discussed in the text are shown. Numbers correspond to locations for which near-IR reflection spectra were obtained, as listed in Table 1.

eigenvalues are shown in Table 2 . The ratio of each eigenvalue to the total sum of all eigenvalues represents the proportion of variance contained in that principal component. These ratios are sometimes referred to as the principal component loadings, and are also given in Table 2 . In the present case, the first two principal components are responsible for over $96 \%$ of the variation in the data. The relationship of the principal components to physically meaningful quantities may be examined by plotting the eigenvectors against wavelength. The eigenvector spectra of Figure 6 show that the first principal component is mainly related to the position and depth of the 1 $\mu \mathrm{m}$ band. The second principal component is sensitive to the spectral slope. Similar interpretations of eigenvector spectra were made by Johnson et al. [1985] and Jaumann [1991]. Principal component scores for the near-IR spectra are calculated by transforming each spectrum by the eigenvectors of Figure 6. Each spectrum may then be located as a single point in PC space (Figure 7). In this plot, the spectral end-members are found at the extremes, and mixtures lie within the boundaries [Smith et al., 1985]. Our observations included four possible end-members: mature and fresh mare, and mature and fresh highlands. It can be seen in Figure 7 that these are well separated by the PCA, plotting approximately at the endpoints of a four-sided figure. Spectra of mixtures of these four, such as dark-halo crater material and light plains surfaces, reside within the area defined by the end-members. The single point away from the main group, labeled 37 , represents a spectrum of a small, extremely fresh crater in the Schickard light plains. The extreme freshness of this crater imparts a very deep absorption band and shallow continuum slope to the spectrum. Therefore it is not a reasonable end-member to consider for the present group of spectra.

The contribution of each end-member to a mixture spectrum can be calculated from the distance of a mixture from each of the end-members in Figure 7. For the present purpose, linear mixing of spectral end-members [Singer and McCord, 1979] is assumed. A linear ("checkerboard") model describes the mixture of components on a macroscopic scale (-centimeter or greater). In other words, multiple scattering of photons is ignored. A linear model is adequate because lunar materials are generally of low albedo and produce little multiple scattering. Also, the study of lunar spectral mixing by Johnson et al. [1985] has shown that results from a linear mixing model do not differ greatly from those assuming nonlinear (intimate) mixing.

Because the mixing model is based on normalized spectra, the abundances represent the contribution of each end-member to the total flux of the modeled mixture spectrum. In order to determine the actual area fractions of the end-members on the lunar surface, the flux fractions must be weighted by the albedos of the endmembers. This is accomplished with the following relationship:

$$
\frac{A_{i} a_{i}}{\sum_{j=1}^{n} A_{j} a_{j}}=f_{i}
$$

where $A_{i}$ is area fraction of end-member $i$ (the unknown), $a_{i}$ is albedo of end-member $i, f_{i}$ is flux fraction of end-member $i$ (calculated from PC scores), and $n$ is the number of endmembers.

Because the spectral observations do not provide information on albedo, it is necessary to use another source. Previous workers have often used the normal albedo maps produced by Pohn and Wildey [1970] or Wildey [1977]. However, the resolution of the hard copy [Pohn and Wildey, 1970] and digital [Wildey, 1977] maps is too low to accurately locate points near the limb, where the SS region is found. Therefore a digital telescopic image of the SS region at $0.99 \mu \mathrm{m}$ (see discussion in the next section) was used to provide relative albedo values.

\section{Multispectral Images}

To gain extended spatial information on the composition of formations in the SS region, a set of multispectral images was analyzed. Two multispectral scenes of the SS region were acquired as part of an imaging survey of the Moon carried out with a $C C D$ array camera attached to a $61-\mathrm{cm}$ telescope on Mauna Kea [Neukum et al., 1991]. Images were obtained in 12 filters: $0.4,0.5,0.55,0.6,0.65,0.72,0.79,0.85,0.89,0.93,0.96$ and $0.99 \mu \mathrm{m}$. The images considered here were collected on August 18, 1989 between 0748 and 0752 UT; the phase angle at the time was $16^{\circ}$. Corrections for extinction, dark current, and flatfield were applied, and images were normalized to a standard exposure time [Neukum et al., 1991]. Images with this degree of calibration (differing from absolute reflectance only by additive bias and linear gain factors) are satisfactory for deconvolution with linear mixing models, as discussed further below. Two image cubes were assembled by registering the two sets of 12 filter images with the SUBPREG routine in the Planetary Image Cartography System (distributed by the U. S. Geological Survey), using the $0.72-\mu \mathrm{m}$ image as a base. Because of large filter-tofilter variations in average data number (DN) value, the cubes were normalized by dividing by the 12-point spectrum extracted from an area on the north mare patch on the floor of Schickard. This prevented filter images with higher DN from overly influencing the mixing model fit, and produced results with smaller residual error than the unnormalized cubes. The two $0.72-\mu \mathrm{m}$ base images were mosaicked together and placed into an orthographic projection.

In order to explore the occurrence and distribution of spectral types, an image mixing analysis was conducted. Image mixing 

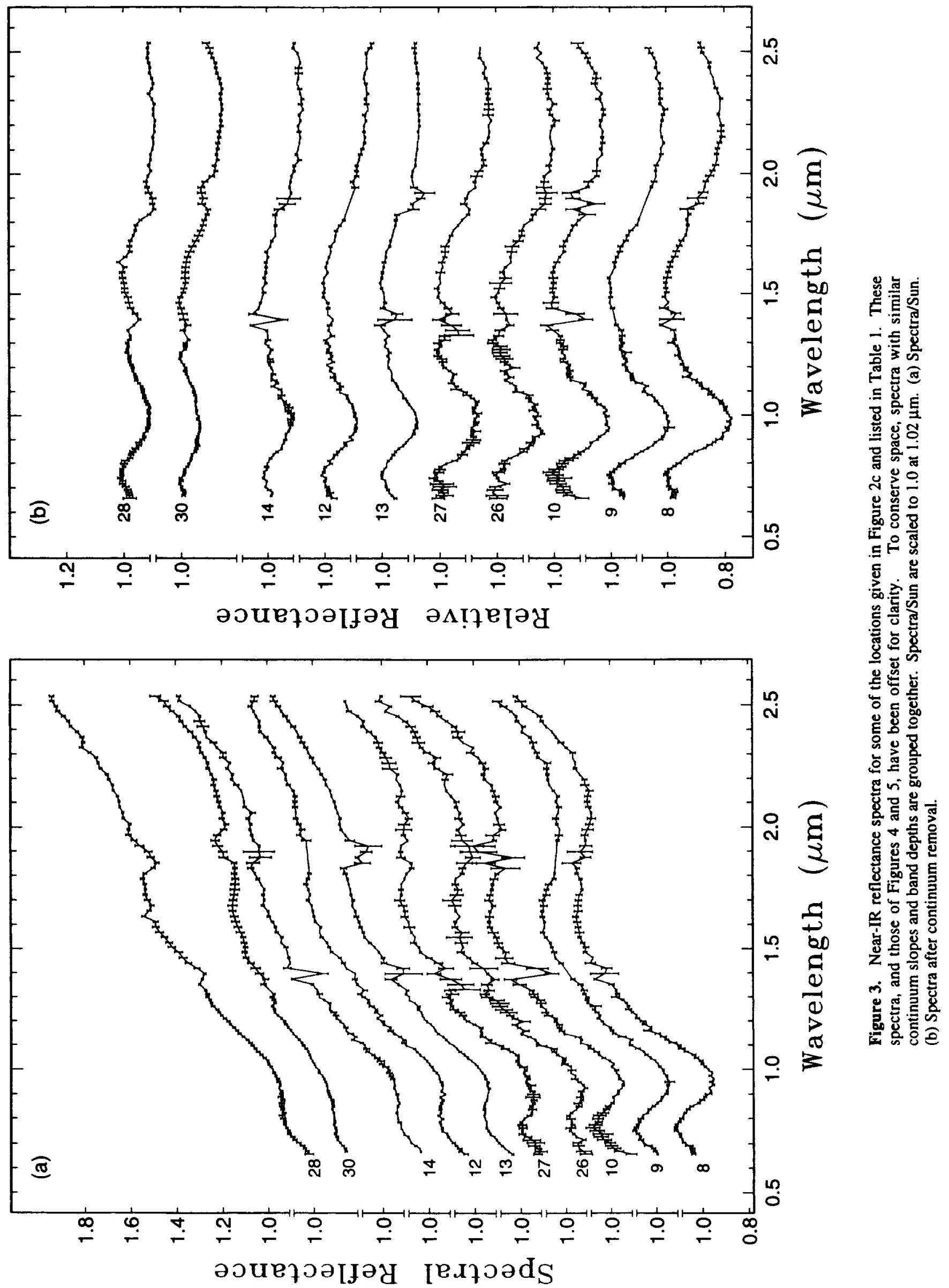
model calculations were executed with a routine in the image processing system described by Kruse et al. [1993]. The program found the best fit end-member fractions for each pixel, subject to the constraints that the individual end-member abundances were $\geq 0$ and the sum of the abundances was $\leq 1$, such that the rms difference between the data and model spectra was minimum. Linear mixing was assumed. Linear models provide good firstorder results and do not require the data to be of high photometric accuracy, as do intimate mixture models.

\section{Results and Discussion}

\section{Near-IR Spectral Findings}

Highlands. To investigate the composition of the preOrientale highland material in the Schiller-Schickard region, two spectra were obtained for Schickard $X$, an $8-\mathrm{km}$ crater in the eastern wall of Schickard (Figure 2). The walls and bowl of this crater should expose highland material from beneath any Orientale-related deposits. One spectrum (31 in Table 1) has a band minimum of $0.92 \mu \mathrm{m}$, a shallow continuum slope of 0.49 $\mu \mathrm{m}^{-1}$, and a weak 5\% depth. These spectral parameters are consistent with an $\mathrm{Fe}^{+2}$-bearing plagioclase-rich assemblage, with low-Ca pyroxene as the dominant mafic mineral. The lithology indicated is a noritic anorthosite. This composition is very common in the southern and western highlands, being similar to that at the Apollo 16 landing site and that found in much of the exterior deposits of Orientale (Hevelius Formation) [Hawke et al., 1991]. A second spectrum (30) has a band minimum slightly longward of the first, at $0.96 \mu \mathrm{m}$, though the

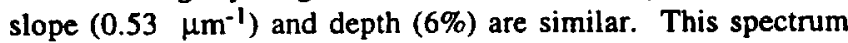
was collected with a smaller aperture. Photographs taken during the course of data collection indicate that the elliptical "footprint" of the aperture on the lunar surface, elongated by the location of the target near the limb, included a small amount of mare basaltbearing area on the floor of Schickard. This is the probable explanation for the longer band minimum. The results of the PCA indicate that the area for which the spectrum was obtained is dominated by noritic anorthosite with minor amounts of mare basalt (Figure 7).

Mare units. Near-IR reflectance spectra were also collected for a variety of mare units in the SS region. These include spectra for mature surfaces on the north and south mare patches within Schickard (numbered 23-25, and 28 in Table 1), and for a mare unit northeast of Schickard in Lacus Excellentiae (spectrum 22). In addition, two observations of a small crater in the Schickard north mare were made (spectra 26 and 27). These spectra have band minima in the range 0.96 to $1.0 \mu \mathrm{m}$; the mature surfaces typically have band depths of $\sim 8 \%$, while the fresh rock surfaces exposed in the mare crater yield spectra with depths of $13-15 \%$. The continuum slopes of the mature mare $\left(\sim 0.7 \mu \mathrm{m}^{-1}\right)$ are slightly steeper than those for the crater $\left(-0.6 \mu \mathrm{m}^{-1}\right)$. The parameters are characteristic of a mafic mineral assemblage dominated by high-Ca pyroxene.

Dark halo craters. The DHCs Drebbel F, Inghirami W, Nöggerath $F$, and Schickard $\mathrm{R}$ were shown by Bell and Hawke [1984] and Hawke and Bell [1981] to have mare basalt signatures, demonstrating that the dark haloes are indeed due to exposed mare basalt. Detailed analysis of the spectra of these craters, including spectra not considered in the previous reports, has been carried out. The results, along with data for another DHC in the region, are discussed below.
Several separate observations of the bowl (spectra 8-10) and ejecta (spectra $12-14$ ) of crater Nöggerath F (48.0 $0^{\circ} \mathrm{S}, 46.9^{\circ} \mathrm{W} ; 9$ $\mathrm{km}$ diameter) were made. The band minima for these spectra range from 0.97 to $0.99 \mu \mathrm{m}$. The bowl of the crater exposes fresh basalt, indicated by the deep bands (19-22\%) and less steep continuum slopes $\left(\sim 0.5 \mu \mathrm{m}^{-1}\right)$. The band depths and continuum slopes of the spectra obtained for the ejecta of Nöggerath F, as well as the locations of the ejecta spectra in PC space (Figure 7), indicate that the basaltic ejecta has not reached the level of maturity of the mare surfaces within Schickard.

Inghirami $W\left(44.4^{\circ} \mathrm{S}, 67.4^{\circ} \mathrm{W} ; 6.5-\mathrm{km}\right.$ diameter $)$ is located west of Schickard, in the continuous deposits of Orientale. Two spectra were collected for the bowl of Inghirami W $(19,20)$, in addition to one spectrum that included both the bowl and the dark halo (18). One bowl spectrum was fairly noisy, making the position of band minimum uncertain. The higher-quality spectrum yielded a band minimum of $0.99 \mu \mathrm{m}$. The determined band depths and continuum slopes for both bowl spectra were similar to each other and very much like those of local mare craters. The spectrum for the area that includes the dark halo exhibits a minimum at $0.98 \mu \mathrm{m}$. The continuum slope and band depth are consistent with a greater level of maturity for the material present in the halo. Inghirami $\mathrm{W}$ clearly exposed mare basalt from beneath the highland-rich unit emplaced as a result of the Orientale impact event.

Three spectra (15-17) of areas on the dark ejecta of Drebbel $F$ crater $\left(42.7^{\circ} \mathrm{S}, 44.6^{\circ} \mathrm{W} ; 15-\mathrm{km}\right.$ diameter $)$ have band minima between 0.95 and $0.98 \mu \mathrm{m}$, consistent with a basaltic regolith. The values for continuum slope and band depth are slightly less than those for nearby mature mare surfaces. It appears that the dark halo of Drebbel $F$ is dominated by mare basalt with small and variable amounts of highland debris. A smaller, unnamed crater has penetrated the northeast rim of Drebbel $F$ and could have contributed some less mafic material to the exterior deposits.

A single large-aperture spectrum was collected for Schickard $\mathrm{R}$, a $5-\mathrm{km}$-diameter $\mathrm{DHC}$ in the Schickard light plains. The observation (33 in Table 1) included the crater bowl and dark halo, as well as some of the light plains [Hawke and Bell, 1981]. The spectral parameters are almost identical to those of mature areas on the nearby mare patches on the floor of Schickard. This crater has clearly excavated mare basalt.

The 84-km-diameter crater Wargentin, just to the southwest of Schickard, has an unusual morphology. Wargentin has a flat floor well above the level of the surrounding terrain and approximately level with the lowest point in the crater wall. A ridge similar to those found on mare surfaces crosses the raised floor, which has a highland-like albedo. A spectrum of the prominent DHC on the southern portion of the floor of Wargentin (spectrum 21) has a band minimum at $0.99 \mu \mathrm{m}$, showing that mare basalt exists beneath the light plains unit. This confirms the hypothesis of Hawke and Bell [1981] that Wargentin was filled with extrusive volcanic material, then covered with a layer of higher-albedo material as a result of the Orientale impact event.

Light plains and cryptomaria. Data gathered by the solid state imaging system (SSI) on board the Galileo spacecraft during the first Earth-Moon encounter have been used to identify a large region in and around Schickard with an enhanced mafic mineral content relative to the surrounding highlands [Belton et al., 1992; Mustard et al., 1992; Head et al., 1993a]. The higher mafic abundance has been interpreted by the Galileo team to reveal the 


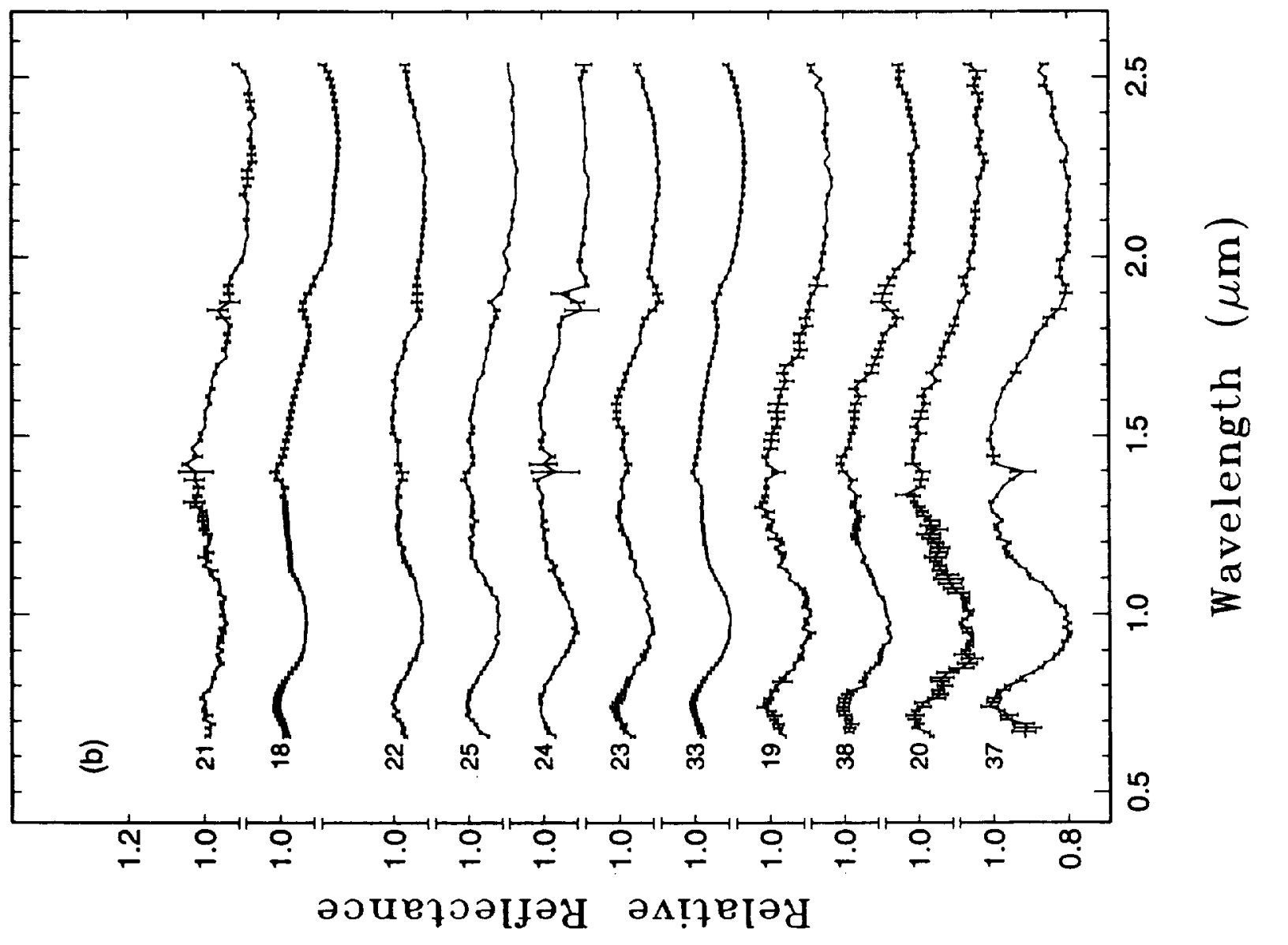

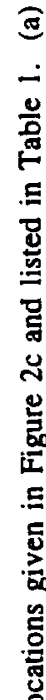

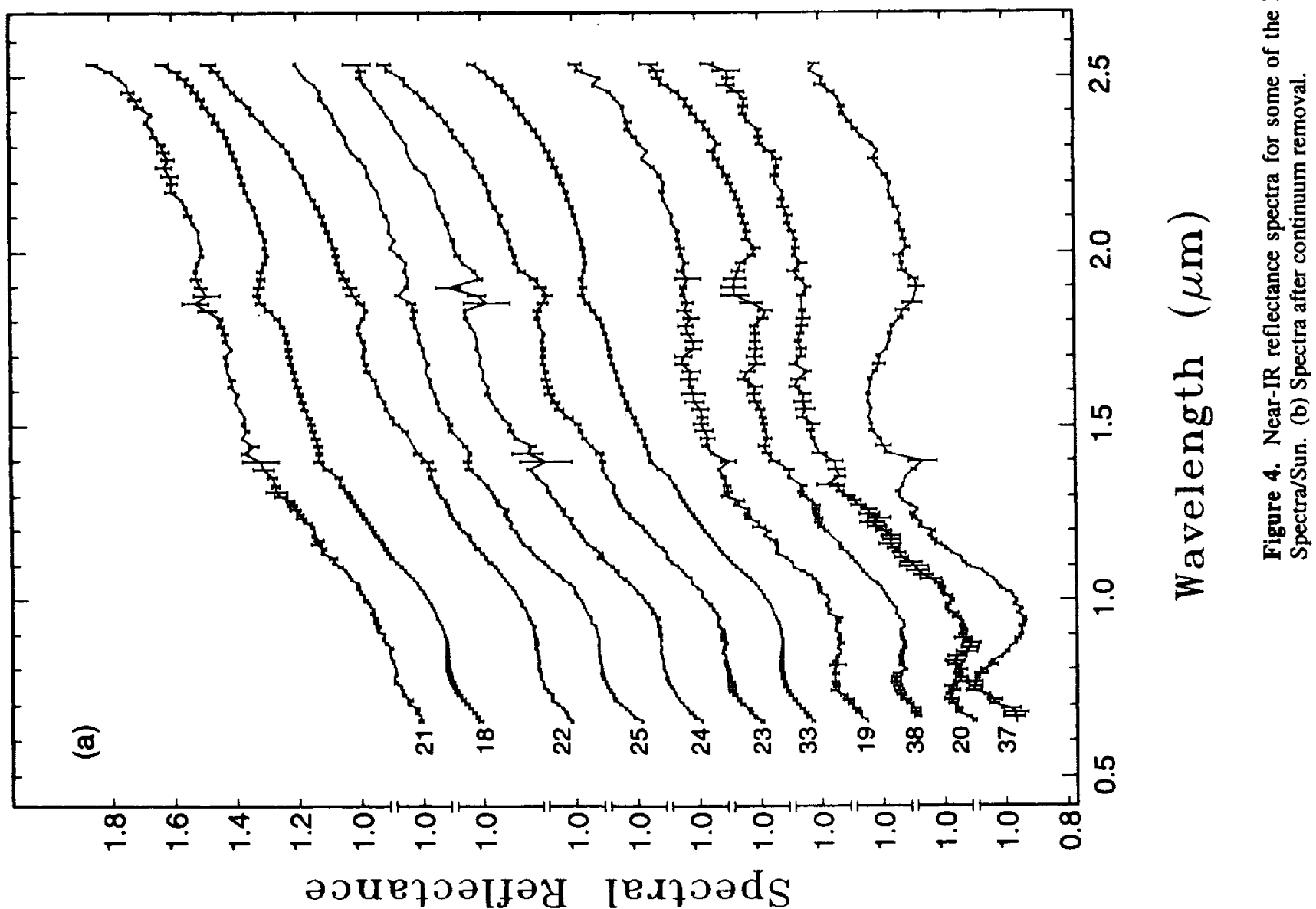




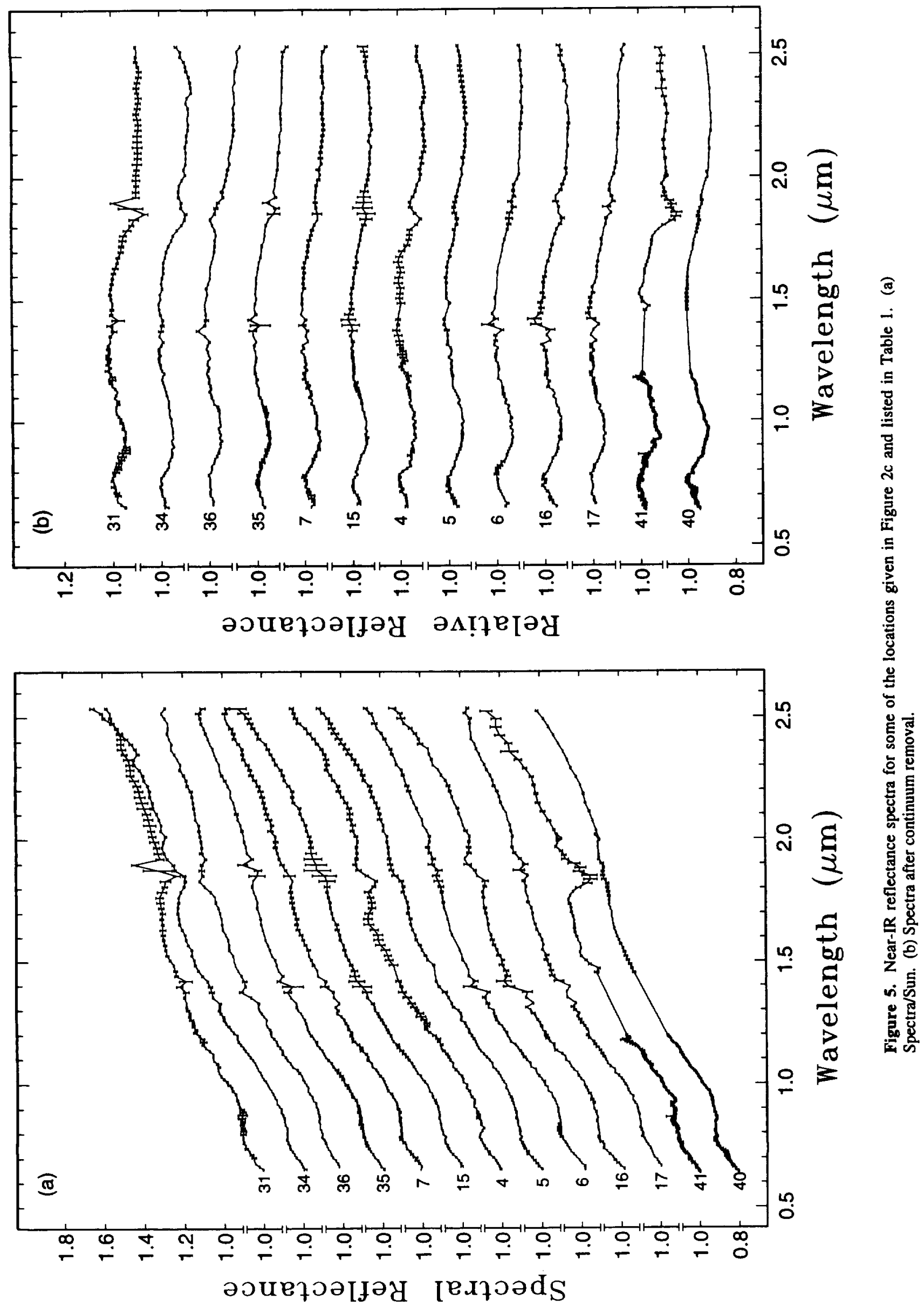


modification and burial of pre-Orientale mare deposits by Orientale ejecta. Extensive portions of this cryptomare correlate with light plains deposits in the SS region.

In order to better understand the nature and origin of the light plains units in the Schiller-Schickard region, near-IR reflectance spectra obtained for small areas on the light plains were analyzed. On the basis of qualitative comparison of absorption band depths, Bell and Hawke [1984] proposed that the light plains on the floors of Schickard and Schiller craters contain a large component of pyroxene-rich material. The spectral parameters derived in the present work allow more detailed analysis. The parameters for three spectra of areas on the light plains on the floor of Schickard (34-36) are given in Table 1. The band minima range from 0.94 to $0.96 \mu \mathrm{m}$, indicating the presence of some high-Ca pyroxene. The strengths of the absorption bands in these spectra (5\%) are slightly greater than expected for a typical mature highland surface. The continuum slope, $0.6 \mu \mathrm{m}^{-1}$, also is intermediate between that of mature highlands and mature mare spectra.

Light plains are also found on the floor of Schiller crater. A spectrum of this deposit (7) has characteristics resembling those of the Schickard light plains. The minimum is at $0.93 \mu \mathrm{m}$, slightly shortward of those for the Schickard light plains, and the continuum slope of $0.6 \mu \mathrm{m}^{-1}$ is the same. However, the band depth of $6 \%$ suggests the presence of either a fresher surface or a slightly higher amount of mafic minerals. Since photographs of the area for which the spectrum was obtained show no fresh craters, a more mafic composition is indicated.

The spectra for the Schickard light plains and the plains on the floor of Schiller lie along a mixing line between mature mare (Schickard mare north 2; spectrum 24) and mature highlands (Apollo 16; spectrum 3) on the PC space plot of Figure 7. A twocomponent mixing analysis for the plains spectra was performed to find the contribution of each end-member to the flux of the observed spectra. Model spectra were computed by mixing the two end-member spectra in the proportions determined from the mixing analysis. A comparison of the original and model spectra is shown in Figure 8, along with the rms error. The model spectra fit the observed data quite well. To convert the flux fractions in the spectra to area abundances on the lunar surface, the DN values of an area on the northern mare unit within Schickard and a spot on the Hevelius formation in the $0.99-\mu \mathrm{m}$ CCD image were used as the mature mare and mature highlands end-member albedos in (1). The results of the conversion to area abundances are given in Table 3.

The mixing model indicates that significant amounts of mare basalt are found in the Schickard light plains, varying from -40 to $67 \%$, depending on the spot observed. This is in accord with the expectations from the band analysis. Similarly, the light plains within Schiller are shown to contain $-70 \%$ basalt.

The spectra of the Schickard and Schiller light plains units discussed above were derived from observations of the mature

Table 2. Eigenvalues and Principal Component (PC) Loadings for the First Four Principal Components Determined for the Schiller-Schickard Spectra

\begin{tabular}{ccc}
\hline PC Axis & Eigenvalue & Total Variance, \% \\
\hline 1 & 0.1203 & 75.9 \\
2 & 0.0320 & 20.2 \\
3 & 0.0025 & 1.6 \\
4 & 0.0008 & 0.5 \\
\hline
\end{tabular}

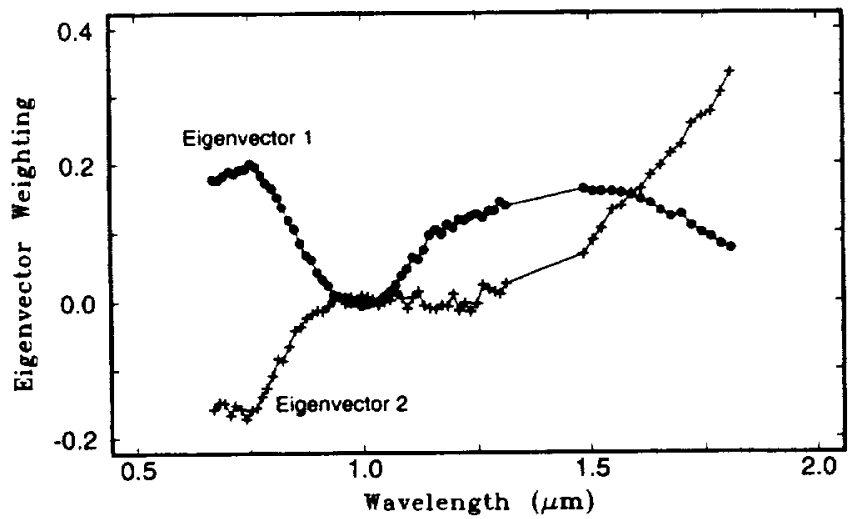

Figure 6. First two eigenvectors computed from PCA of Schiller-Schickard spectra.

upper surfaces of these deposits and clearly demonstrate the presence of major amounts of mare material. Is this mare component present throughout the entire thickness of the light plains or just at the surface? An enrichment only in the surface could be explained by lateral transport of material from impacts in nearby post-Orientale mare units, or more likely by exhumation of buried mare basalt from beneath the light plains unit by post-Orientale impact craters. An enrichment of mare material throughout the depth of the light plains would be expected if a local mixing process had operated during the emplacement of the plains. In order to answer this important question, two spectra were obtained for a small $(-1.4 \mathrm{~km}$ diameter), very fresh unnamed crater in the Schickard light plains. This impact crater excavated material from a variety of depths within the light plains unit. A crater with this diameter should be approximately $280 \mathrm{~m}$ deep. However, the vast majority of the ejecta was derived from the upper $140 \mathrm{~m}$ of the preimpact target site. Although the thickness of the Schickard light plains deposit is variable, it is well over $200 \mathrm{~m}$ thick in the area where this small crater formed and the material excavated and redeposited by the impact originated in the interior of the

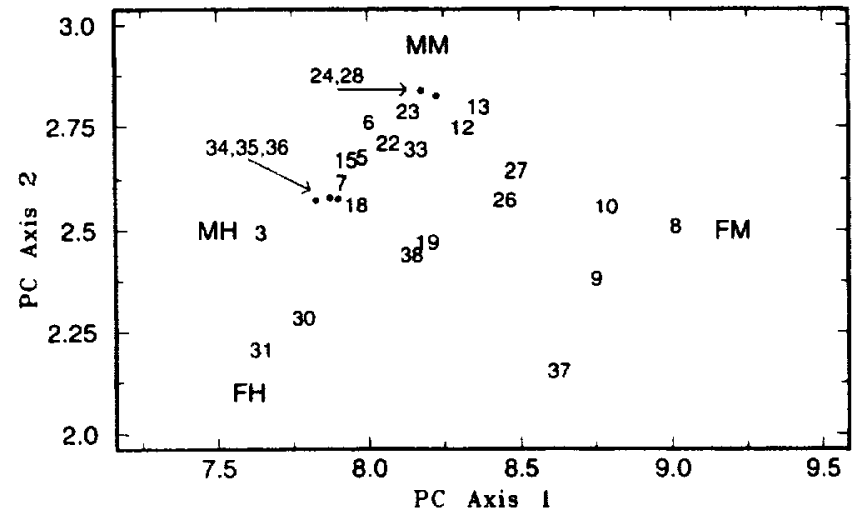

Figure 7. Schiller-Schickard spectra projected into principal component space. The numbers identify spectra listed in Table 1. Four plausible spectral end-members were included in the PCA, and these plot near the extremes of a four-sided figure. The endmembers are indicated by MM (mature mare), FM (fresh mare), $\mathrm{MH}$ (mature highlands), and FH (fresh highlands). Spectrum 37 is for a small, unusually fresh crater, and is therefore not a useful end-member in the present case. 
light plains unit. The composition of the fresh crater material should provide important information concerning the lithology of the subsurface portions of the Schickard light plains. The spectrum recorded for the small crater and its ejecta blanket (spectrum 38) exhibits a relatively strong absorption band $(-12 \%)$ with a band minimum near $0.96 \mu \mathrm{m}$. The spectral parameters indicate the presence of a sizable mare component in the area for which the spectrum was obtained. A second spectrum was collected for the interior of the crater (spectrum 37). This spectrum also has a band minimum near $0.96 \mu \mathrm{m}$, but the band is stronger $(-20 \%)$ and the continuum slope is very shallow. The crater interior contains a large amount of mare basalt.

In order to determine the amount of mare material present within the light plains unit, a mixing analysis was conducted for the spectrum obtained for the interior and exterior deposits of the small crater. The results of a two-component (fresh mare, fresh highlands) mixing model indicated that the crater deposits contain $44 \%$ immature mare material. A three-component model (fresh mare, fresh highlands, mature highlands) yielded similar results: $46 \%$ immature mare basalt. These results clearly show that mare basalt is a major component in the material that makes up the Schickard light plains. Mare basalt is present throughout the entire thickness of the deposit, and is not just a surface enrichment in the regolith, as would be expected from lateral transport or vertical mixing.
Schiller-Zucchius plains. The Schiller-Zucchius plains (which correspond in part to the "Schiller Plains" of Offield [1971]) lie to the west and southwest of Schiller crater and occupy a portion of the Schiller-Zucchius basin (Figure 2). This area, which has a lower albedo and lower crater density than the surrounding highlands, has been previously mapped as "dark plains" and attributed to ash deposits [Offield, 1971]. However, the material of the Schiller-Zucchius plains exhibits mare-type ridges which are roughly radial to Orientale, appears to embay the adjacent terrain, and floods some small ruined craters, including Orientale secondaries. These morphologic characteristics are more consistent with post-Orientale mare basalt flows than pyroclastic deposits. The results of recent radar studies of the SS region have indicated that extensive dark mantle deposits of volcanic ash are not present [Hawke et al., 1993].

Five telescopic observations were made to gain compositional information for surfaces on the Schiller-Zucchius plains (spectra 4-6, 40, and 41). The spectra have bands with minima from 0.95 to $0.98 \mu \mathrm{m}$ and depths of $6-8 \%$; the continuum slopes are 0.60 $0.68 \mu \mathrm{m}^{-1}$. Thus the spectra are indicative of mare basalt, though some of the band depths are slightly less and the positions of some of the minima are slightly shortward of the values determined for spectra of the mare patches in Schickard. The likely explanation for these spectral parameters is a minor admixture of highland material contaminating a post-Orientale mare surface. Mixing analysis conducted on two of the Schiller-

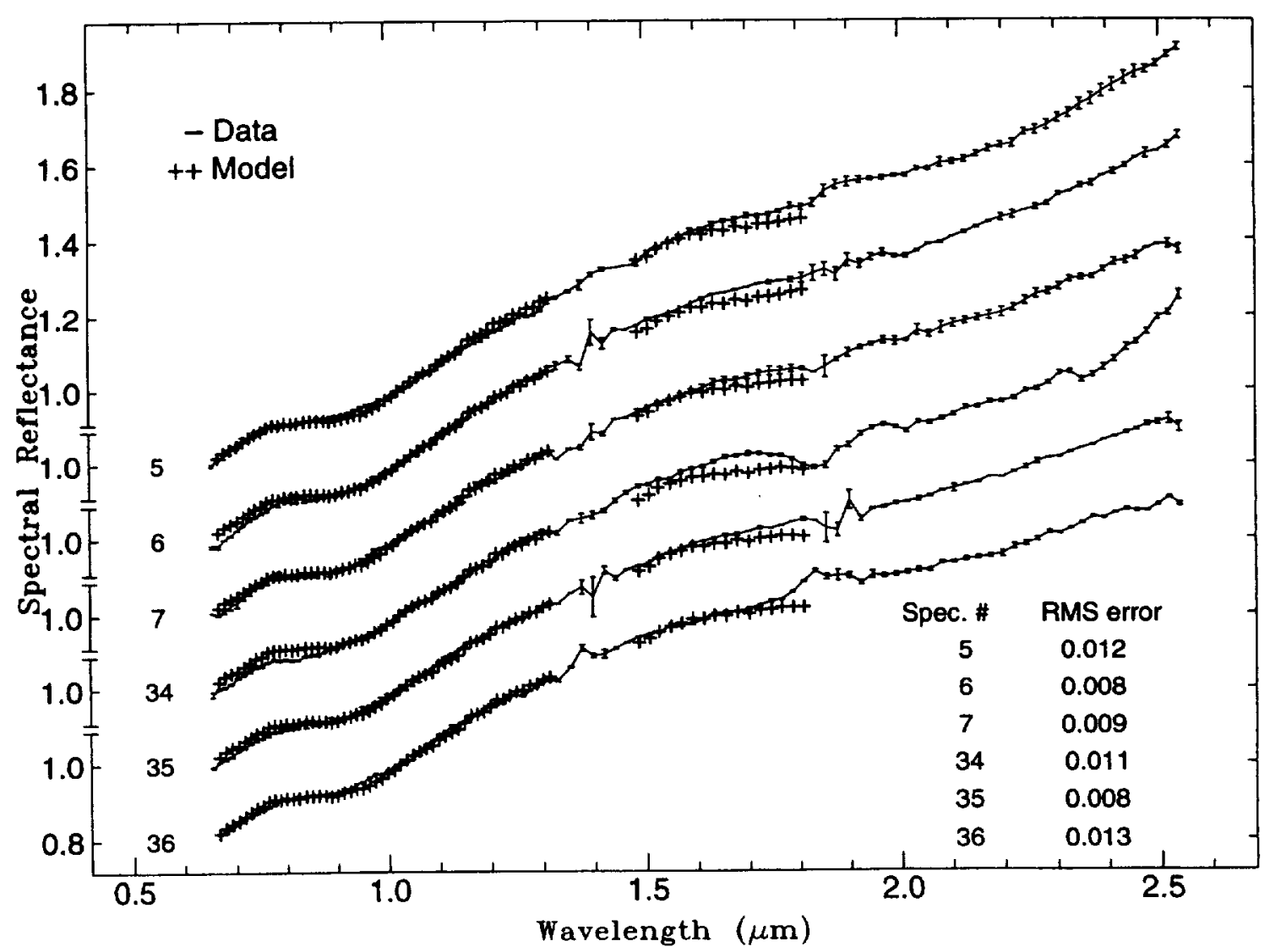

Figure 8. Comparison of telescopic spectra for light plains and related units with model spectra calculated from two-component PCA mixing analysis. The numbers on the left identify spectral locations given in Table 1. Overall error of the model fit is shown in the lower right. Note that the model fits are quite good in the area of the important " $1-\mu \mathrm{m}$ " mafic mineral absorption band. Portions of the original spectra near atmospheric water absorptions $(1.4$ and $1.9 \mu \mathrm{m}$ ) and longward of $2.0 \mu \mathrm{m}$ (thermal contamination) were not included in the analysis. 
Table 3. Two-End-Member Spectral Mixing Model Results Based on PCA for Light Plains and Related Surfaces in the SS Region

\begin{tabular}{|c|c|c|c|}
\hline Spectrum & Spot Name & $\begin{array}{c}\text { Mature } \\
\text { Highlands, \% }\end{array}$ & $\begin{array}{l}\text { Mature } \\
\text { Mare, \% }\end{array}$ \\
\hline 5 & $\begin{array}{l}\text { Schiller-Zucchius } \\
\text { Plains N }\end{array}$ & 18 & 82 \\
\hline 6 & $\begin{array}{l}\text { Schiller-Zuccchius } \\
\text { Plains } 3\end{array}$ & 15 & 85 \\
\hline 7 & Schiller floor & 30 & 70 \\
\hline 34 & Schickard center & 59 & 41 \\
\hline 35 & $\begin{array}{l}\text { Schickard Light } \\
\text { Plains } 1\end{array}$ & 41 & 59 \\
\hline 36 & $\begin{array}{l}\text { Schickard Light } \\
\text { Plains } 2\end{array}$ & 33 & 67 \\
\hline
\end{tabular}

Given are area abundances of mature highlands (Apollo 16) and mature mare (Schickard mare N 2) end-members

Zucchius plains spectra (similar to that described in the previous section) shows that a combination of $-15 \%$ highland debris with $85 \%$ mare material can provide a good match (Figures 7,8 , Table 3). The 64-km-diameter Copernican-age crater Zucchius is located $-250 \mathrm{~km}$ to the southwest. Zucchius rays and secondary craters are found on the Schiller-Zucchius plains [Offield, 1971; Hawke and Bell, 1981], making Zucchius the likely chief source of the highland contamination.

Crater statistics presented by Greeley et al. [1993] indicated a model age of $3.70 \mathrm{Ga}$ for the Schiller-Zucchius plains. Figure 11 of Greeley et al. [1993] shows the area labeled "SchillerZucchius plains" for which crater counts were made. However, close examination of available Lunar Orbiter photography and comparison with the map of Offield [1971] clearly show that small areas of Orientale secondary crater cluster material were included in the area mapped as Schiller-Zucchius plains by Greeley et al. [1993]. These workers noted that the model age of $3.70 \mathrm{Ga}$ is younger than the Orientale and Imbrium impacts, and that it is unlikely that the Schiller-Zucchius plains can be attributed to material emplaced as a result of these basin-forming events. They suggested that the plains may be ejecta deposits of adjacent, younger craters, such as Zucchius, or possibly of other origin.

The results of our analysis suggest a fairly straightforward origin for the Schiller-Zucchius plains. Mare basalts were emplaced at $-3.70 \mathrm{Ga}$. These lavas embayed adjacent terrain and flooded preexisting Orientale secondary craters. The wrinkle ridges that are generally radial to Orientale may have been formed by the flooding of Orientale secondary crater chains that are roughly radial to the basin. These mare deposits were subsequently contaminated by a minor amount of highland debris transported to the area as a consequence of the Zucchius and other impact events [Blewett et al., 1992]. We thus restrict the term "Schiller-Zucchius plains" to indicate the post-Orientale mare deposits near Schiller that have received minor highland contamination.

\section{Analysis of Multispectral Images}

The near-IR spectra are of high spectral resolution, enabling detailed mineralogical information to be extracted. However, they are of limited spatial extent. In order to gain increased areal coverage, multispectral images may be employed. A previous study has used Galileo SSI images from the first Earth-Moon encounter to investigate the abundance of mare basalt in the area of the Schickard cryptomare [Head et al., 1993a]. Analysis by the Galileo team has focused on imagery in five colors between 0.41 and $0.99 \mu \mathrm{m}$, at spatial resolution ranging from 3.9 to 29.0 $\mathrm{km} /$ pixel [McEwen et al., 1993]. We present here results based on analysis of Earth-based telescopic multispectral images covering about the same wavelength range, but sampled at a higher spectral resolution ( 12 filters). Additionally, the spatial resolution of the telescopic images, $-2 \mathrm{~km} / \mathrm{pixel}$, is higher than that of the SSI data.

The telescopic data set consists of two multispectral scenes (Figure 9). Scene A covers the southwestern limb of the Moon and includes the northern mare deposit in Schickard and part of the light plains unit on that crater's floor. Scene B, to the east of scene $A$, contains the southern mare unit in Schickard, the Schiller-Zucchius plains, and Schiller crater. A linear mixing analysis was performed so that the distribution of spectral types could be examined. Initial trials utilized an unconstrained model in which end-member fractions can take on any value. This allows the number and location of potential end-members to be rapidly evaluated. Following this process of testing and refinement, four end-member spectral types were finally chosen as the average of small groups of pixels within the scenes. The end-members were (1) mature highlands, an area on the limb highlands free of bright craters; (2) fresh highlands, bowl and wall material of crater Inghirami C; (3) mature mare, an area of the north mare unit on the floor of Schickard crater; and (4) fresh mare, bowl of Nöggerath F crater. The selection of these endmembers accords with the PCA of the near-IR spectra (Figure 7), which indicated the presence of two mare and two highland spectral types.

For the "final" mixing analysis, both image cubes were unmixed using the constrained model (end-member fractions must be $\geq 0$ and sum to $\leq 1)$ and the four end-members described above. Constraint violations occurred in a small number of pixels ( $<1.5 \%$ of the total), mostly because of a few small craters that are brighter than the selected end-members. The analysis produced an abundance image for each of the end-members, an image depicting the sum of the end-member fractions, and an rms error image. The error images for each scene show that good fits $(-1 \%)$ were obtained over the whole region, with the exception of higher misfit values associated with bright craters. The two mature mare abundance images were mosaicked together and reprojected to match the $0.72-\mu \mathrm{m}$ image.

The mature mare end-member abundance image (Figure 10) reveals that significant amounts of mare basalt occur in the surface units in and around Schickard and the terrain to the east, including the Schiller-Zucchius plains and the area surrounding Schiller crater. Elevated mare abundances are found outside of the readily identifiable low albedo post-Orientale mare deposits. West of Schickard, the limb highlands are mostly free of a mare component. The light plains on the floor of Schickard stand out with proportions of mature mare basalt mostly in the range 25 $75 \%$; the average total mare fraction (fresh+mature) in light plains pixels is $-45 \%$. These findings are in good agreement with those of the mixing model studies utilizing near-IR spectra, which indicated the presence of $\sim 40-67 \%$ mare basalt in the surface at several isolated areas on the Schickard light plains unit. It is interesting to note that the average total mare basalt abundance in Schickard light plains pixels as determined from the multispectral images (45\%) is in excellent agreement with the amounts of mare material (44-46\%) present in the ejecta of the $1.4-\mathrm{km}$ light plains crater as determined by mixing model analysis of near-IR spectra.

The light plains on the floor of Schiller crater have an average 


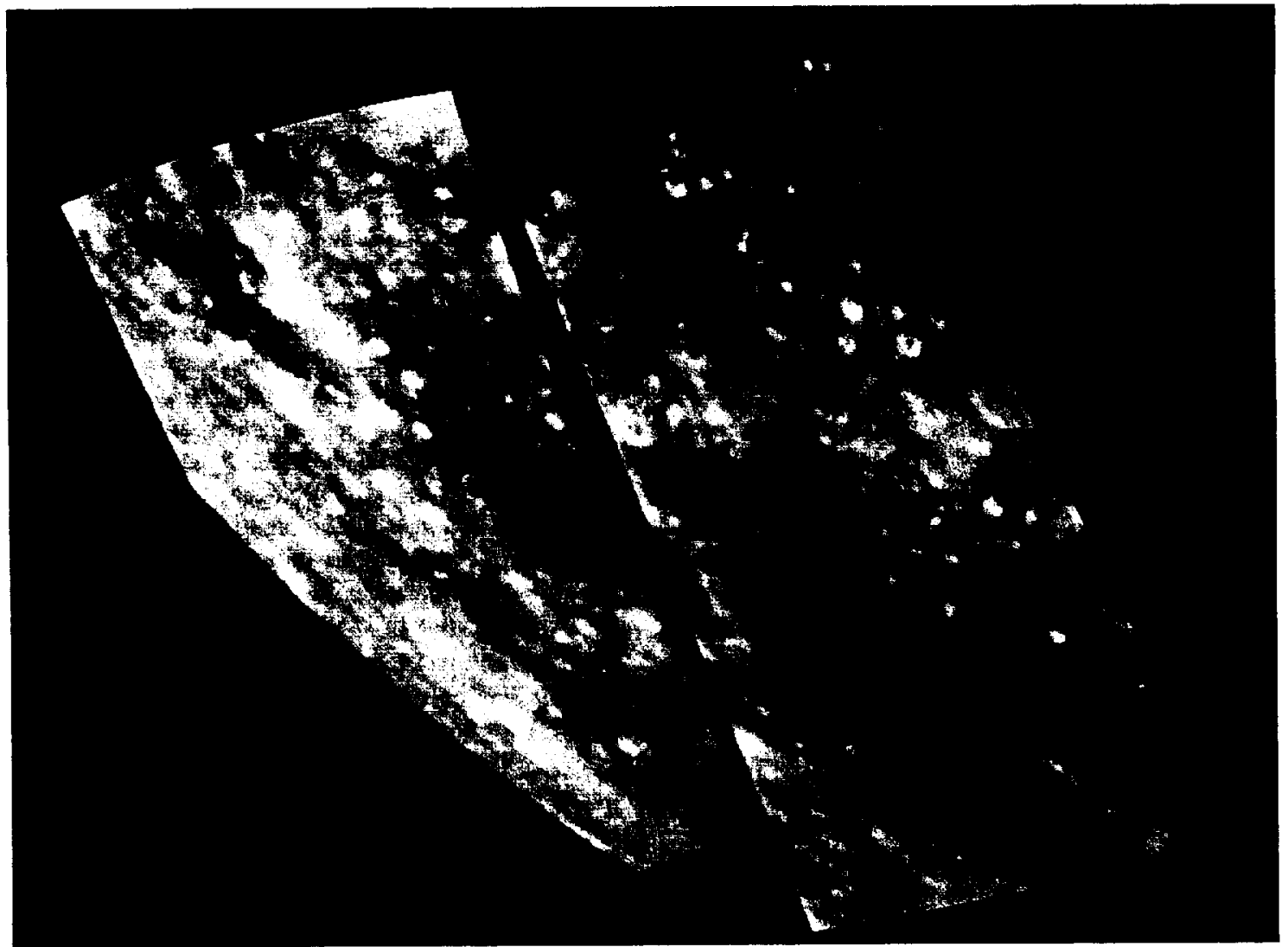

Figure 9. CCD images of the Schiller-Schickard region made through a $0.72-\mu \mathrm{m}$ filter. The images have been placed in an orthographic projection centered at $\left(0^{\circ}, 0^{\circ}\right)$. Compare with Figures $2 a, 2 b$, and $2 c$.

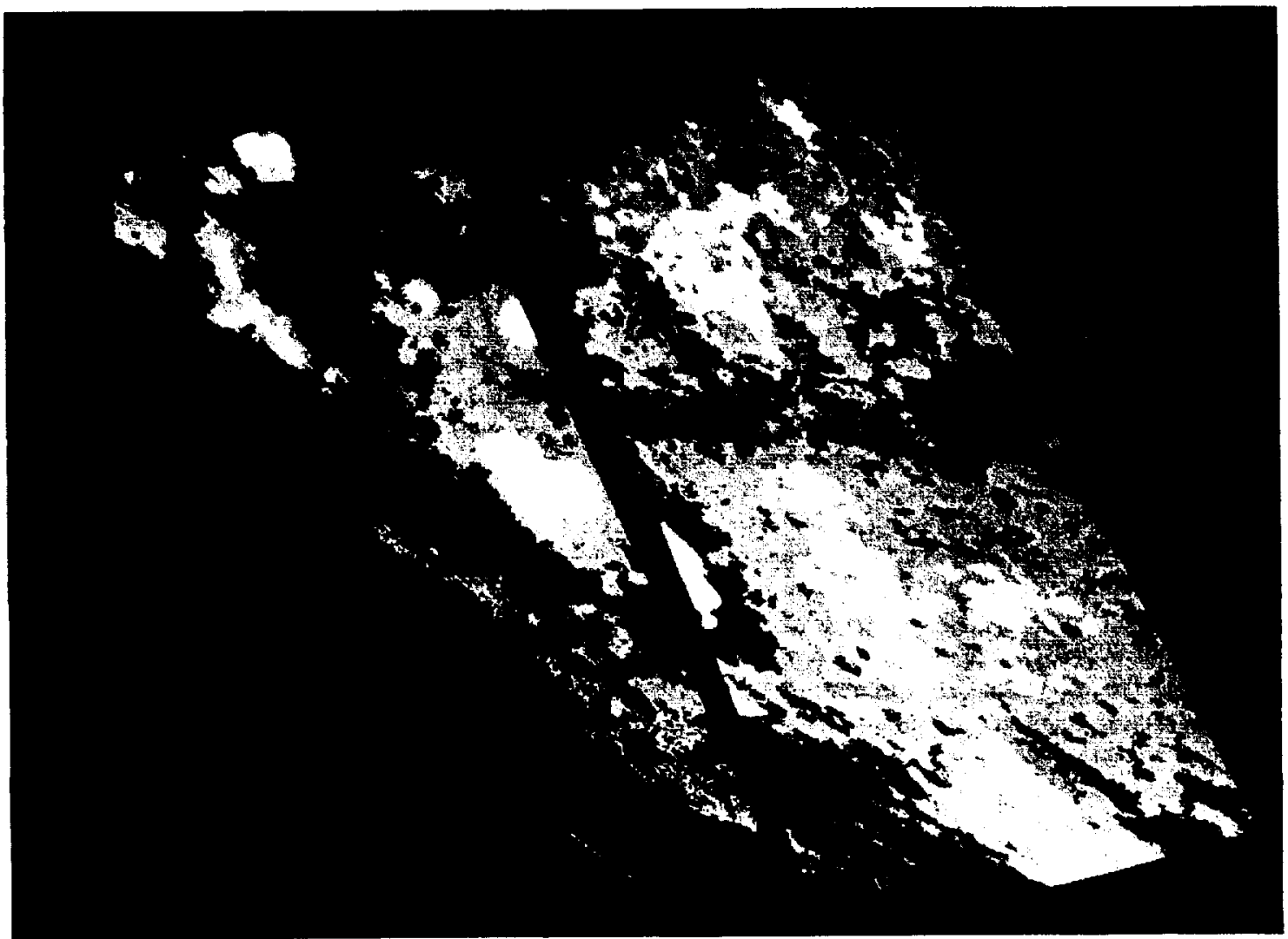

Figure 10. Results of image spectral mixing analysis. Shown is the model abundance of the mature mare endmember, density sliced to $25 \%$ increments. Black, 0-25\%; dark grey, 26-50\%; light grey, 51-75\%; white, 76-100\%. The projection is the same as that of Figure 9. 
mature mare abundance of about $40 \%$, though small areas on the north central part of the floor where the near-IR spectrum was obtained exhibit mature mare fractions approaching $60 \%$. The spectral mixing model described above found $70 \%$ basalt for the Schiller floor spectrum.

High mare basalt abundances also exist in the vicinity of the DHC's Drebbel $F$ and Nöggerath $F$, and the post-Orientale Schiller-Zucchius plains are shown to be dominated by mare basalt (Figure 10). Portions of the Schiller-Zucchius plains display mare fractions $>75 \%$; this is in accordance with the results from the spectra which suggested $\sim 85 \%$ mare component. The present findings are in good agreement with those reported by Mustard et al. [1992] and Head et al. [1993a].

In a later section we will discuss the importance of the results of remote sensing studies for understanding the processes that occurred during the emplacement of the distal deposits of impact basins and explaining the presence of significant amounts of mare basalt in the Schiller-Schickard light plains as a consequence of the interaction of Orientale primary ejecta with preexisting mare deposits. The mixing model results shown in Figure 10 clearly indicate that the highland units in the SchillerSchickard region generally contain large amounts of mare basalt. The modeled percentages generally range between $25 \%$ and $75 \%$. The results for the light plains in Schiller crater and Schickard crater were discussed above, but numerous other light plains deposits occur in the region and these also exhibit relatively high abundances of mare material. In a few areas, the amounts of mare debris in the light plains exceeds $75 \%$, but areas with 50 75\% are much more common. It is important to note that large expanses of nonplains highland terrain in the SS region also exhibit abundances of mare basalt that range between $25 \%$ and $75 \%$.

One possible explanation for the large amounts of mare basalt associated with the light plains units in the SS region is that pure highland debris was emplaced on top of preexisting mare units as a consequence of the Orientale impact event, and that mare material was excavated and added to the regolith by subsequent impact cratering events. Is this vertical mixing scenario viable? The bulk of the evidence suggests that it is not. First, evidence was presented in a previous section that the subsurface portion of the light plains unit in the floor of Schickard crater contains $-45 \%$ mare material. If vertical mixing was responsible for the high percentage of mare material associated with the SS light plains, one would expect that this mare component would be concentrated in the near-surface layer and absent at depth. This is not true for the light plains on the floor of Schickard. Second, the distribution of mare-rich material in the region argues against the vertical mixing hypothesis. As shown in Figure 10, most highland units in the SS region exhibit mare abundances in excess of $25 \%$. The enhanced mare abundances are not confined to the light plains; they also occur in elevated and relatively rugged areas that were unlikely to have been the site of preOrientale mare volcanism. Additional evidence was presented by Pieters et al. [1993]. They noted that SSI spectrum 74 has a very strong ferrous absorption band at $\sim 1 \mu \mathrm{m}$ and that its spectral properties indicate the presence of a large amount of freshly exposed mare basalt. This SSI spectrum was derived for a small, fresh crater on a highland ridge between the craters Nasmyth and Phocylides. It is unlikely that mare basalts were erupted on this ridge after the formation of Nasmyth and Phocylides. A more probable explanation is that ancient mare basalts were disrupted by Orientale secondary-forming projectiles and incorporated into a debris flow which moved radially away from Orientale and deposited mare-rich material on the ridge. This process appears to offer the best explanation for the presence of an abundant mare component in other elevated and rugged terrain downrange from light plains units that display dark-haloed impact craters.

The origin of the light plains on the floor of Schiller is uncertain. As discussed above, these plains possess an average mare abundance of almost $40 \%$. Greeley et al. [1993] presented crater statistics that yielded a model age of $3.73 \mathrm{Ga}$ for the Schiller floor light plains. If this age is correct, mare basalt was extruded on the floor of Schiller at $-3.73 \mathrm{Ga}$ and subsequently contaminated by highland lithologies emplaced by vertical mixing and lateral transport processes. However, the postOrientale Schiller-Zucchius plains, which lie closer to Zucchius crater and exhibit obvious Zucchius rays and secondary craters, are less contaminated with highland material.

Another possibility exists for the origin of the light plains on the floor of Schiller. According to the alternate hypothesis, these plains were emplaced as a consequence of the Orientale impact event and the mare component results from the excavation of preexisting basalts by Orientale secondaries and the incorporation of this mare material into the radial-flowing debris surge that moved across the interior of Schiller. At present, evidence exists both for and against each mode of origin. Additional information will be required to resolve this issue.

Finally, it should be noted that enhanced mare basalt abundances exist in the highland terrain surrounding Lacus Excellentiae and other mare units south of Mare Humorum. This area can be seen in the upper portion of Figure 10. Mare abundances of $25-50 \%$ are common in light plains and other highland units in this area. Similar enhancements can also bee seen in the mare abundance images presented by Mustard et al. [1992] and Head et al. [1993a]. It seems likely that cryptomaria are present in this area. The emplacement of ancient, preOrientale mare basalts in this region may have been facilitated by the presence of a topographic depression within a large impact structure located between the Humorum basin and the SchillerZucchius basin.

\section{Implications for the Local Mixing Hypothesis and the Emplacement of Distal Basin Deposits}

The processes responsible for the emplacement of the distal deposits of lunar impact basins have long been the source of considerable debate. Distal deposits are the outer portions of the ejecta units surrounding large impact structures. Four possible modes of emplacement are illustrated in Figure 11. These have been discussed in detail by a number of workers [e.g., Eggleton and Schaber, 1972; Chao, 1974; Oberbeck, 1975; Oberbeck et al., 1974, 1975a,b; Head and Hawke, 1975; Hawke and Head, 1978; Moore et al., 1974; Wilhelms, 1987]. One model (Figure 1 la) emphasizes the importance of surface flow. According to this hypothesis, basin material is transported for long distances (hundreds of kilometers) as a ground-hugging debris flow. When the flow comes to rest, a layer of primary basin material has been deposited atop local material. The second possible mode of emplacement is shown in Figure 11b. In this model, material is excavated from the transient crater and travels in ballistic trajectories to the point of impact and deposition. There is no surface flow and minimal interaction with the substrate. Hence, primary basin ejecta is deposited on top of local, nonbasin material. Figure $1 \mathrm{lc}$ represents a third possible mode of distal basin ejecta emplacement. According to this model, primary basin ejecta is transported for relatively long distances in ballistic 
flight and, upon reimpact, moves as a surface flow for tens of kilometers. There is little or no significant reworking of the preimpact surface, and when the flow comes to rest, a layer of primary basin ejecta lies above the local material. Finally, the ballistic erosion and sedimentation model of Oberbeck and coworkers is depicted in Figure $11 \mathrm{~d}$.

The model of Oberbeck and co-workers [Oberbeck et al., 1974, 1975a,b; Oberbeck, 1975; Morrison and Oberbeck, 1975], which has become known as the ballistic erosion and sedimentation or local mixing hypothesis, considers secondary cratering to be a major process in modifying and redistributing material on the lunar surface. In the Oberbeck model, the velocity component of the secondary crater ejecta radial to the primary gives rise to a debris surge which moves outward behind the ejecta curtain. At large distances from the primary, the mass ejected from the secondary craters can exceed the mass of the primary ejecta projectiles that formed them. Thus the debris surge entrains material of both primary and local origin, with local material dominating the distal deposits. The ejecta curtain and debris surge are similar to the two regimes of transport envisioned by Eggleton and Schaber [1972]: one ballistic and the other highly fluidized and able to flow over obstacles and pool in depressions. However, Eggleton and Schaber [1972] postulated a fluidizing medium of melted or vaporized rock, and also considered the deposits to consist predominantly of primary ejecta.
Oberbeck et al. [1975a] developed equations to calculate the degree of local mixing produced by secondary cratering as a function of the size of the secondary craters formed, the angle at which the secondary-forming projectiles strike the surface, and the distance from the primary impact. Thus the model may be tested if there is some available means to distinguish between the primary ejecta and the substrate with which the ejecta interacts; this is not often the case. One example where this has been attempted is for the rays of Copernicus crater, which were formed by the interaction of highland-rich primary ejecta with a mare basalt substrate. A study of the rays by Pieters et al. [1985] found that the proportion of mare to highland spectral types in the rays was consistent with the ballistic erosion model. The light plains deposits in the Schiller-Schickard region offer a rare opportunity to determine the relative amounts of primary ejecta and secondary crater ejecta (i.e., local material) because the composition of Orientale primary material is very different from the substrate (mare basalt) present in large portions of the Schiller-Schickard region at the time of the Orientale impact event [Hawke et al., 1991; Head et al., 1993a]. Hence it is possible to evaluate the local mixing hypothesis for the origin of the distal deposits of the Orientale basin.

In order to apply the Oberbeck equation, Orientale secondary craters in and near Schickard were identified on Lunar Orbiter IV photographs with the aid of the map by Karlstrom [1974], and the diameters measured. A range of values was found, from a few

\section{Possible Means of Distal Basin Ejecta Emplacement}
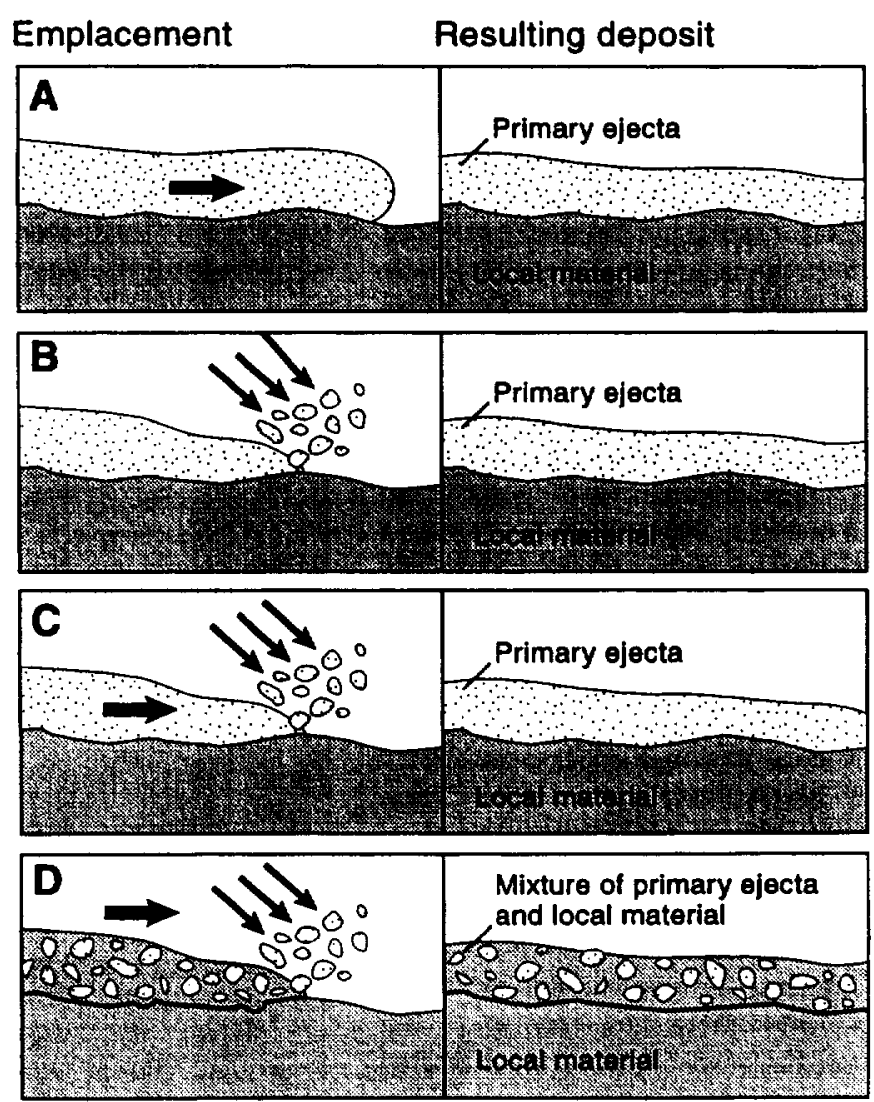

Figure 11. Representation of possible modes of basin ejecta emplacement. (a) Surface flow. (b) Ballistic emplacement. (c) Ballistic emplacement induces surface flow. (d) Ballistic erosion and sedimentation. For each, the left panel depicts the emplacement process and the right panel shows the resulting deposit. 
kilometers for craters found in small groups, to as a much as 14 $\mathrm{km}$ for some isolated secondaries. The radial distance from the ejection point within the primary impact to the secondary crater cannot be exactly determined, so an average distance was used equal to the distance from the transient cavity rim to the secondary, plus one-half of the transient cavity radius. For Orientale, the transient cavity rim was taken to be the Outer Rook mountains [Head, 1974]. The great circle distance from the Outer Rooks to the center of Schickard crater is approximately $958 \mathrm{~km}$. The diameter of the Outer Rook ring is $620 \mathrm{~km}$ [Wilhelms, 1987], so the distance used in the Oberbeck equation was $958+(620) / 4=1113 \mathrm{~km}$. The Oberbeck equation is not strongly dependent on the radial distance, and variations of plus or minus $100 \mathrm{~km}$ (representing slight differences in the distance to the individual measured secondaries) do not cause substantial changes in the outcome of the calculation. The impact angle was taken to be $75^{\circ}$ from the vertical. The equation of Oberbeck et al. [1975a] expresses the degree of local mixing as a ratio $\mu$, equal to the mass of the excavated local material divided by the mass of the secondary-forming projectile. The proportion of local material is thus given by $\mu /(\mu+1)$, and this quantity has been plotted in Figure 12. Also shown is a curve given by the original Oberbeck relation modified by a change in the assumed impact scaling law, as suggested by $H$. J. Moore (quoted by Wilhelms [1987, p. 211]).

The plotted values in Figure 12 indicate that for the secondary crater sizes encountered near Schickard, the expected fraction of local material ranges from about $40-80 \%$. The remote sensing data presented in the previous section indicate that the amount of mare basalt contained in the Schickard light plains is generally $40-67 \%$, with an average of about $45 \%$. The abundances of mare basalt were also determined for two extensive clusters of Orientale secondary craters located adjacent to the SchillerZucchius plains southeast of Schickard (Figure 2). The northern cluster (approximately centered at $47^{\circ} \mathrm{W}, 51.7^{\circ} \mathrm{S}$ ) contains craters that range from a few kilometers to $8 \mathrm{~km}$ in diameter. The southern cluster $\left(-47^{\circ} \mathrm{W}, 55.5^{\circ} \mathrm{S}\right)$ has larger craters that are 5 to $15 \mathrm{~km}$ in diameter. Calculations made according to the methods described above indicate that the amounts of local material associated with the northern cluster should range between $45 \%$ and $85 \%$. The calculated fractions of local material in the southern cluster are between $42 \%$ and $82 \%$. The results of our image mixing model analysis indicate that the material associated with the secondary crater clusters in the Schiller-Zucchius area is dominated by mare debris. The abundances of mare basalt typically range between $50 \%$ and $75 \%$ (Figure 10). These results generally agree with the values presented by Mustard et al. [1992] and Head et al. [1993a]. Therefore, the extent to which local material was incorporated into the distal deposits of the Orientale basin by secondary craters is in general accord with the predictions of the ballistic erosion model.

While the validity of the local mixing hypothesis has been demonstrated, it should be noted that the amounts of local material present in the distal deposits of Orientale are rarely equal to the maximum values predicted by the original Oberbeck equation. A number of factors could contribute to a decreased proportion of local material. The first set of factors is related to the assumptions underlying the ballistic erosion model as presented by Oberbeck and co-workers. In some areas, the remote sensing results match the predictions of the modified Oberbeck relation more closely than those of the equation in its original form. Therefore the scaling relation between crater diameter and impact energy of the modified model may be more nearly correct. In addition, Schultz and Gault [1985] have emphasized that secondary craters are likely to be formed by fragmented projectiles. They performed laboratory scale impact studies which demonstrate that disrupted impactors displace less target material than do single-body impactors. Therefore, the Oberbeck relation, which was developed using assumptions from the study of laboratory and explosion analogs of single-body impacts, could overestimate the cratering efficiency of secondaries.

However, there are geological factors that could also account for abundances of mare basalt less than the maximum values predicted by the original Oberbeck relation. Chief among these is contamination of Orientale-related deposits by highland materials from nearby impacts in the time since the Orientale basin-forming event. While this effect is probably minor for the light plains on the floor of Schickard crater, it is important for the Orientale secondaries adjacent to the Schiller-Zucchius plains. As discussed above, the Schiller-Zucchius plains are a postOrientale mare deposit. The surfaces of even the darkest portions of this mare unit contain $-15 \%$ highland debris contributed by Zucchius and other post-mare impacts. Hence, it seems likely that the nearby Orientale secondary clusters have been contaminated by at least $15 \%$ highland material from Zucchius and other craters. The southern cluster, which is closer to Zucchius, may have been contaminated by even greater amounts of highland debris.

The evidence provided by the distribution of DHC's in the SS region was used by Hawke and Bell [1981] and Bell and Hawke [1984] to argue that the pre-Orientale mare deposits in the area were widespread and discontinuous, similar to the present-day appearance of Mare Australe [Whitford-Stark, 1979]. The thin, patchy nature of the pre-existing mare units would mean that less basalt was available for incorporation into the deposits resulting from the impact of Orientale primary ejecta. In addition, large Orientale secondary craters (10-15 km in diameter) could have easily excavated highland material from beneath thin (hundreds of meters) mare units. Since many portions of the discontinuous pre-Orientale mare deposits appear to be relatively thin, it is not surprising that the larger Orientale secondary-forming projectiles

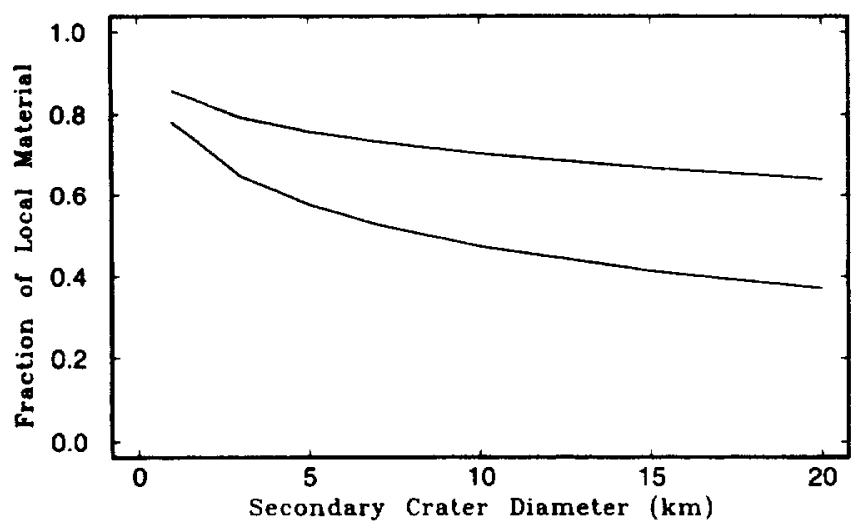

Figure 12. Fraction of local material in Orientale-related deposits at the distance of Schickard as a function of secondarycrater diameter, calculated from the relation developed by oberbeck et al. [1975a]. The top curve represents the results from the original Oberbeck equation. The lower curve was computed with the Oberbeck equation modified by a change in the assumed impact scaling law [Wilhelms, 1987]. The impact angle in both cases was assumed to be $75^{\circ}$ from the vertical. 
penetrated the mare units and incorporated subjacent highland debris into the resulting deposit.

In summary, the results of both near-IR spectral studies and a mixing model analysis of multispectral images demonstrate that large amounts of local mare basalt are present in light plains and other distal deposits of the Orientale basin in the SchillerSchickard region. The local material is present throughout the entire thickness of the light plains. The local mare basalt is not just a surface concentration introduced by vertical mixing from beneath the Orientale ejecta deposit. Orientale secondaryforming projectiles excavated local mare material and incorporated this debris into the resulting deposits. The amounts of local material (pre-Orientale mare basalt) present in the light plains and other units in the SS region emplaced as a consequence of the Orientale impact event approach, but rarely exceed, the maximum values calculated using the original Oberbeck relationship. While the original Oberbeck equation may overestimate the cratering efficiency of secondaries, there are a number of geologic factors that could also account for abundances of local mare materials that are less than the values predicted by Oberbeck. These include the thin, discontinuous nature of the ancient mare units in the SS region, as well as the contamination of Orientale-related deposits by highland debris emplaced by nearby impacts in the time since the formation of the Orientale basin. While certain questions remain, the reality of the "local mixing" hypothesis has been demonstrated.

\section{Implications for Ancient (>3.8 Ga) Volcanism and the Origin of Lunar Light Plains}

The spectral data discussed above, as well as the results of previous studies [Hawke and Bell, 1981; Bell and Hawke, 1984] clearly demonstrate that dark-haloed impact craters in the Schiller-Schickard region expose mare basalts from beneath highland-rich surface units emplaced as a consequence of the Orientale basin-forming event. No observed dark-halo crater exhibits spectral evidence for darkening of the ejecta by projectile contamination or other processes. DHCs are numerous and widespread in areas of the Schiller-Schickard region where little or no recognized mare volcanism has occurred (Figure 2; [Schultz and Spudis, 1979, 1983; Bell and Hawke, 1984]). Bell and Hawke [1984] identified more than 15 DHCs in the region, and Antonenko and Head [1994] have mapped 27 dark-haloed impact craters in the vicinity. Both the distribution of DHCs (Figure 2a) and the occurrence of mare basalt-bearing highland units (Figure 10) indicate that the areal extent of the pre-Orientale mare deposit is much greater than had previously been thought.

The ancient Schiller-Zucchius basin (Figure 2c), centered to the southwest of Schiller [Hartmann and Kuiper, 1962], appears to have played a significant role in the concentration of early $(>3.8 \mathrm{Ga})$ mare basalt on this portion of the lunar surface. Impact basins produce topographic lows in addition to extensive crustal fracture systems. Both of these factors have been shown to be conducive to the extrusion and accumulation of volcanic material [e.g., Solomon, 1975; Head and Wilson, 1992]. Based on crater diameter distribution studies and morphologic evidence, Hartmann and Wood [1971] suggested that the Schiller-Zucchius basin had been flooded to a depth of $3 \mathrm{~km}$ by early volcanic materials. More recently, Antonenko and Head [1994] have presented evidence that the thickness of buried mare basalt in the Schiller-Schickard cryptomare varies from 1 to $2 \mathrm{~km}$. Outside of the core cryptomare region within the Schiller-Zucchius inner ring, the thickness appears to be considerably less (i.e., hundreds of meters).

Enhanced mare basalt abundances exist in the highland terrain surrounding Lacus Excellentiae and other mare units south of Mare Humorum (Figure 10). As noted in a previous section, mare abundances of $25-50 \%$ are common in light plains and other highland units in this area. A heretofore undescribed cryptomare exists around Lacus Excellentiae. The distribution of this cryptomare appears to have been influenced, at least in part, by a previously unmapped multiring impact basin located between the Schiller-Zucchius basin and the Humorum basin. The basin is most evident on Lunar Orbiter IV image 137-M (Army Map Service version). The main ring of this basin is approximately $440 \mathrm{~km}$ in diameter. Since the craters Schickard and Mee are superposed on this ring, we propose that this impact structure be named the Schickard-Mee basin (Figure 2c). Several segments of an outer ring can be identified and there is a possible poorly defined inner ring. The Schickard-Mee basin is very degraded and clearly formed prior to the Schiller-Zucchius and Humorum impact structures. In the areas where the Schiller-Zucchius outer ring is superposed on the Schickard-Mee outer ring, the former is topographically low and poorly defined. The presence of the Schickard-Mee basin also interfered with the development outer rings of the Humorum basin. The outer Humorum rings become indistinct at the points where they intersect the Schickard-Mee structure.

The formation of the Schickard-Mee basin produced a topographic low, a thinner crust, and major crustal fractures. These factors would have promoted the emplacement of ancient mare basalts within the Schickard-Mee impact structure. The emplacement of mare deposits and the deposition of ejecta from nearby impact basins have largely filled the topographic depression. The distribution of cryptomare in the SS region appears to have been controlled by the occurrence of large impact basins (Schickard-Mee, Schiller-Zucchius, Humorum).

The existence of very old ( $>3.8 \mathrm{Ga}$ ) mare basalt deposits may help to explain the occurrence of some of the light plains units formerly believed to be the products of highland volcanism or other processes. In the area of Schiller and Schickard, many light plains are certainly underlain by pre-Orientale basalt, and their surfaces are composed of material whose near-infrared spectral properties are intermediate between those of mature mare and mature highlands. Bell and Hawke [1984] used spectral data originally presented by Charette et al. [1974] to demonstrate that many nearside Imbrian age light plains exhibit spectral parameters $(0.40 / 0.56$ and $0.56 / 0.95 \mu \mathrm{m}$ ratios) that plot in a distinct region separate from other mature highlands areas and overlapping the mature mare. Bell and Hawke [1984] suggested that some of these deposits were similar in composition to the light plains in the Schiller-Schickard region and that they may have a common origin as basin-related materials emplaced on flat basaltic plains. Bell and Hawke [1984] further noted that the distinctive spectral properties of certain nearside light plains may be a result of mixing between basin ejecta and preexisting mare deposits during the emplacement process, or by later vertical mixing.

The existence of flat expanses of terrain should facilitate the formation of light plains deposits by debris surges produced by the impact of secondary-forming projectiles ejected by large (basin-size) impacts. The results of a variety of remote sensing and geologic studies of the SS region indicate that the occurrence of pre-Orientale mare basalt deposits played an important role in the production of light plains in this portion of the lunar nearside. 
